ISSN 0717 - 2877

Universidad de Talca - Facultad de Ciencias Jurídicas y Sociales

Incorporación de las minas a la categoría del dominio público. Historia de su discusión doctrinaria y situación actual

Michelle Azuaje Pirela

Trabajo recibido el 28 de enero de 2018 y aprobado el 23 de julio de 2019

\title{
Incorporación de las minas a la categoría del dominio público. Historia de su discusión doctrinaria y situación actual
}

\author{
INCORPORATION OF MINES TO THE PUBLIC DOMAIN CATEGORY. HISTORY OF THE DOCTRINAL DISCUSSION AND \\ CURRENT SITUATION
}

Michelle AzUAJe PiRela ${ }^{1}$

\section{RESUMEN}

En los estudios doctrinarios sobre los regímenes mineros a nivel mundial ha sido una preocupación constante tratar de responder, entre otras cosas: ¿A quién pertenecen las minas o la riqueza mineral?, ¿Cuál es la relación que existe entre los particulares y el Estado con las minas? ¿Qué naturaleza tienen los derechos que se pueden adquirir sobre la riqueza mineral? Las teorías que se han planteado para responder a estas y otras cuestiones, pueden hallarse en lo que en la doctrina se ha denominado "dominio minero" o para algunos "propiedad minera,", términos que hacen referencia fundamentalmente a la determinación de a quién pertenecen la mina y los recursos minerales, $u$ otros sistemas de ordenación que tratan de explicar el vínculo existente entre el Estado y estos, así como la forma en la que los particulares pueden o no aprovecharlos. Aunque en el derecho comparado parece claro que las minas están integradas al género "dominio público", categoría macro que incluye a una serie de bienes y derechos sometidos a una normativa especial, de la que el dominio minero es entonces, una especie; en el caso de Chile, esto no ha sido así siempre. Al menos desde el punto de vista dogmático. De la revisión de la literatura chilena puede observarse que, salvo excepciones, aún existen vestigios de teorías civilistas para intentar explicar dicho vínculo. De esta forma, aunque el Estado suele estar vinculado con las minas o con la riqueza minera, en Chile la explicación sobre la naturaleza jurídica de ese vínculo es en un principio difusa, habiéndose formulado como una verdadera propiedad, pero luego se les afecta definitivamente a un interés general. De ahí que el presente trabajo busca explicar que, efectivamente, en la actualidad las minas se han venido a integrar a la noción de "dominio público" que incluye las más diversas categorías de bienes.

\section{ABSTRACT}

In the doctrinal studies on the mining regimes it has been a constant concern to try to answer, among other things: To whom do the mines or mineral wealth belong? What is the relationship that exists between individuals and the State with

\footnotetext{
${ }^{1}$ Abogada, Universidad del Zulia. Máster en Derecho de la Empresa, Universidad de Alcalá de Henares. Doctora en Derecho, Universidad Autónoma de Chile. Profesora e Investigadora, Instituto de Investigación en Derecho, Universidad Autónoma de Chile, Chile. Correo electrónico: michelle.azuaje@uautonoma.cl. Nota aclaratoria previa: El presente trabajo forma parte de la tesis doctoral titulada: "Fundamentos de la tributación minera: un estudio del derecho chileno a la luz del derecho español". La tesis fue redactada por la autora entre los años 2015 y 2018, bajo la tutoría de los profesores Dr. Patricio Masbernat (Chile) y Dr. César García Novoa (Universidad de Santiago de Compostela, España) y fue leída en diciembre de 2018. En particular, se presentan los resultados parciales de su Capítulo I titulado "Contexto de la actividad minera: cuestiones fundamentales del régimen jurídico de la minería". En las secciones tres, cuatro y cinco de dicho Capítulo, se realizó una reconstrucción de la categoría doctrinaria de origen francés "dominio público". Asimismo, se explicó cómo fue su desarrollo y acogida en el derecho español, para llegar a dilucidar cómo fue vagamente incorporada y relacionada tal categoría con el dominio público minero chileno. Este análisis histórico-jurídico permitió a la autora concluir que, a pesar de las diferencias entre los ordenamientos mencionados, del escaso y confuso desarrollo doctrinario de dicha categoría, incluso en Chile las minas forman parte del "dominio público" razón por la cual en este trabajo se prefiere hacer uso de dicho término. Sin perjuicio de que dado que en Chile, el legislador no emplea expresamente tal término (pues distingue entre "bienes públicos," "bienes nacionales" y "bienes fiscales"), puede ser considerado un extranjerismo. Considerando además que existe literatura de derecho minero que no hace mención a las bases que aquí se presentan. Cabe destacar asimismo, que, en el período comprendido entre el envío de este artículo y su aceptación, fue publicada la obra de CORDERO (2019), en la que se realiza un análisis con estructura similar a la que se presenta en este artículo y la tesis. De la lectura de dicha obra se desprende (aunque no de forma expresa), que el autor ratifica la posición ya sostenida por esta autora en la tesis doctoral, en cuanto a que es esta la forma adecuada para reconstruir y entender las bases del dom inio público; aunque para él, en el caso de Chile se descartan las influencias francesa y española para plantear su "Teoría de los bienes públicos y los bienes nacionales".
} 
the mines? What is the nature of the rights that can be acquired over mineral wealth? The theories that have been proposed to answer these and other questions can be found in what has been called in the doctrine "mining domain" or for some "mining property," terms that fundamentally refer to the determination of who do the mine and mineral resources belong to, or other legal systems that try to explain the link between the State and these, as well as the way in which individuals may or may not take advantage of them. Although in comparative law it seems clear that mines are integrated into the public domain genre, a macro category that includes a series of goods and rights subject to special regulations, of which the mining domain is then a species; in the case of Chile, this has not always been the case. At least from the dogmatic point of view. From the review of Chilean literature, it can be observed that, with some exceptions, there are still vestiges of civilist theories to try to explain this link. In this way, although the State is usually linked to mines or mining wealth, in Chile the explanation of the legal nature of this link is at first diffuse, having been formulated as a true property, but then being definitively affected to a general interest. Hence, the present work seeks to explain that, indeed, today the mines have come to be integrated into the notion of "public domain" that includes the most diverse categories of goods.

PALABRAS CLAVE

Dominio público, bienes públicos, propiedad minera, dominio eminente, dominio minero.

KEY WORDS

Public domain, public goods, mining property, eminent domain, mining domain.

\section{Introducción}

El objeto en torno al cual gira la actividad minera es precisamente la mina, concepto que lleva aparejados algunos elementos que corresponde conciliar al ordenamiento jurídico de cada país. Como quiera que se entiendan el concepto de mina y de actividad minera, existen diversos intereses en juego, que hacen a esta actividad distinta de otras. De las particularidades de las minas en tanto que en ellas pueden hallarse o acumularse sustancias del reino mineral, se derivan algunas consecuencias que la diferencian de otras producciones de la naturaleza; ya que se caracterizan por hallarse habitualmente ocultas en el subsuelo, siendo necesario buscarlas y luego investigar sus propiedades; casi nunca estar formadas por las sustancias que interesan, pues pueden incluir materiales carentes de valor e incluso nocivos, por lo que es preciso separar; $y$, porque sus recursos son agotables, ya que las sustancias minerales no se renuevan. Se trata de un recurso natural no renovable, lo que significa que una vez utilizados se pierden definitivamente.

Asimismo, en general las minas se suelen considerar bienes independientes de los terrenos en cuya superficie o subsuelo se encuentran. Por lo tanto, jurídicamente se hace necesario determinar si es que coinciden o no en una sola persona, la calidad de propietario de la superficie y la de minero. ${ }^{2}$ Corresponde a cada ordenamiento jurídico, entre otros aspectos, la determinación de cómo habrán de conciliarse ambas propiedades u otros derechos en caso de haberlos. Por lo que los regímenes mineros se han preocupado por tratar de resolver, entre otros, aspectos como los siguientes: ¿A quién pertenecen las minas o la riqueza mineral? ¿Cuál es la relación que existe entre los particulares y el Estado con las minas? ¿Quién y de qué forma puede aprovecharlas? ¿Qué naturaleza tienen los derechos que se pueden adquirir sobre la riqueza mineral y cuál es el procedimiento para adquirirlos? ¿Coinciden en una sola persona la titularidad del suelo y el subsuelo? ¿Qué normas rigen las relaciones entre los propietarios del suelo y subsuelo en el que se halla la riqueza mineral ${ }^{3}$ Las respuestas que con aciertos y desaciertos se han planteado para responder a estas cuestiones, pueden encontrarse a través de lo que en la doctrina se conoce con

\footnotetext{
2 OSSA (2012), p. 13.
}

${ }^{3}$ OSSA (2012), p. 13. 
los términos "dominio minero" o para algunos "propiedad minera"4, los cuales hacen referencia fundamentalmente a la determinación de a quién pertenecen la mina y los recursos minerales, $u$ otros sistemas de ordenación que tratan de explicar el vínculo existente entre el Estado y los recursos minerales, así como la forma en la que los particulares pueden o no aprovecharlos.

Si bien en la actualidad en el derecho comparado parece claro que las minas están integradas al género "dominio público", categoría macro que incluye a una serie de bienes y derechos sometidos a una normativa especial, de la que el dominio minero es entonces, una especie, en el caso de Chile, esto no ha sido así siempre, ni ha sido unánime, existiendo diversidad de denominaciones al respecto; pero es a través de la sólida obra de Vergara Blanco que se vincula a las minas con la categoría del "dominio público" en el ordenamiento chileno. Al menos desde el punto de vista dogmático. Y es en ese sentido que se orienta el análisis que se presenta en este trabajo. Así, aunque no es propósito de este trabajo profundizar e innovar en el escabroso mundo de las distintas teorías que se han extendido a través de la historia para explicar el dominio público y en especial el dominio minero, se propone sí, aportar una aproximación suficiente que permita responder desde una perspectiva dogmática ¿a quién pertenecen las minas? Pero sobre todo aquella vieja pregunta sobre ¿cuál es la naturaleza jurídica del vínculo que existe entre el Estado y las minas? ¿Se integran las minas a la categoría del dominio público? Preguntas estas que sirven como punto de partida para el diseño de los regímenes jurídicos mineros.

\section{Teorías tradicionales o sistemas de ordenación minera}

Antes de comenzar con el análisis que se propone, conviene precisar que, tanto en el derecho administrativo como en el derecho minero, han existido diversas teorías que buscan explicar fundamentalmente si es que debe reconocerse la existencia de un propietario originario de las minas, o si estas pudieran ser explotadas libremente sin atención a ninguna situación jurídica preexistente. En todo caso, aunque el vínculo que pueda existir entre el Estado y/o los particulares con las minas, viene dado fundamentalmente por el establecimiento de normas constitucionales y legales, que fijan sus límites y aquellos que el Estado tiene con uno de sus elementos esenciales, el territorio o espacio, "de todas las riquezas naturales quizás ninguna ofrezca tantas dificultades para hallarle su dueño originario (si es que hay alguno), como las riquezas mineras" ${ }^{\text {. }}$.

Por eso, debe advertirse que las teorías que más adelante se comentarán, no son perfectamente trasladables a cada ordenamiento jurídico, son construcciones doctrinales, y su manera de entenderlas en cada uno de ellos obedece generalmente a un contexto teórico, histórico y político determinado.

Del mismo modo, es importante destacar que en el caso del derecho chileno, en el desarrollo de los textos jurídicos que estudian los regímenes mineros, si bien el Estado suele estar vinculado con las minas o con la riqueza minera, la naturaleza jurídica de ese vínculo es en un principio difusa, habiéndose formulado como una verdadera propiedad, pero luego como se

\footnotetext{
${ }^{4}$ Expresiones integradas a la noción de dominio público o propiedades especiales que no están exentas de discusión. PUYUELO (1954), p. 5, utiliza la expresión "propiedad minera". Por su parte si bien GONZÁLEZ (1998), p. 31, explica que en España las minas pasaron de ser patrimoniales a ser incluidas en el dominio público en la Ley de Minas de 1868, apoyándose en GALLEGO ANABITARTE, opina que tal inclusión supone el principio del fin del dominio público como una institución coherente, pues a su decir, se trata de un error conceptual grave entre otras cosas porque modifica las notas características del régimen demanial, ya que ese dominio público que como bienes de uso común y general tenía las características desde la Baja Edad Media de ser inalienables e imprescriptibles, en este caso se iban a enajenar a perpetuidad. En términos similares se pronuncia VERGARA (2001), pp. 213-216 y VERGARA (2014), pp. 633-654, para quien es irreal que exista un dominio o propiedad del Estado sobre las minas.

${ }^{5}$ ZÚÑIGA (2005), p. 67.
} 
observará, se les afecta definitivamente a un interés general, lo que viene a constatar que en la actualidad las minas forman parte integrante del dominio público ${ }^{6}$. De ahí que el presente trabajo busca explicar que efectivamente las minas se han venido a integrar a dicha noción que incluye las más diversas categorías de bienes.

No obstante lo anterior, antes de entrar de lleno en la teoría del dominio público debe hacerse necesaria mención a otras teorías que desde sus orígenes suelen invocarse en los textos de derecho de minería, como aquellas que explican el vínculo del Estado con las minas. Respecto a ellas se advierte que la aplicación de una no necesariamente excluiría la aplicación de otra, pues es posible encontrar sistemas en los que coexistan por criterios tales como distribución geográfica, competencias territoriales y/o tipos de minerales. Así, la interpretación o aplicación de los sistemas o teorías que a continuación se explican, si bien pueden no ser exactamente iguales en cada ordenamiento, comparten algunos rasgos esenciales que han permitido agruparlas, enunciarlas y diferenciarlas como las siguientes:

\section{a) Sistema Fundiario o de la Accesión}

Conforme a este sistema, el propietario de la superficie lo es también del subsuelo en profundidad ilimitada, por tanto, también de las minas subyacentes. Encuentra sus bases en el concepto de propiedad, considerada en toda su amplitud, y de acuerdo con la cual se estima que lo accesorio sigue a lo principal, siendo el suelo lo principal y el subsuelo lo accesorio ${ }^{7}$, evitándose con ello el inconveniente de la "doble propiedad", esto es, la superficial y la del subsuelo. Entre las objeciones que se han formulado a esta teoría puede mencionarse, que resulta inadecuado atribuir al subsuelo y su posible riqueza un carácter de accesorio con respecto al suelo, más aún cuando suele ocurrir que el valor de una mina o yacimiento ubicado en el subsuelo sea por demás superior al valor del suelo ${ }^{8}$. También se objetó que el propietario de la superficie podría oponerse a los avances de la actividad minera si en el subsuelo de su fundo se encontrasen yacimientos de importante valor económico existiendo una riqueza sin utilización, debiendo privar el interés colectivo frente al interés particular.

Si bien en el nacimiento de la industria minera tuvo amplia aceptación ${ }^{9}$, en la actualidad se ha relegado su aplicación a regular la explotación de minerales considerados de menor importancia por encontrarse a menudo en la misma superficie, se trata de minerales tales como piedras no preciosas, esto es, las rocas, arcillas, arenas, etc. ${ }^{10}$ ya que para otros minerales se ha considerado

\footnotetext{
${ }^{6}$ VERGARA (1992), p. 174.

7 DE ARCENEGUI (2002), p. 44; GUAITA (1986), p. 318; GONZÁLEZ (1969), p. 129; PADILLA (1950), p. 23; PUYUELO (1954), p. 6; ORTIZ (1992), pp. 89 y ss. Véase también: FRANCISKOVIC (2016), p. 145; VILDÓSOLA (1999), p. 107. Según explica CATALANO (1999), p. 62, en el derecho argentino también se le ha llamado "sistema de la propiedad inmobiliaria," porque atribuye la propiedad de las minas, o facultades amplias de disposición, al dueño del terreno en que se encuentran situadas. Para este sistema las minas no tienen caracteres propios, forman parte integrante del inmueble superficial y siguen su condición jurídica. Por consiguiente, el derecho del propietario del suelo a la explotación de estas sustancias no es de carácter originario sino derivado, o indirecto, ya que es derivado el título del dominio de la generalidad de los inmuebles que actualmente se poseen y del cual deriva su derecho de uso y goce. El dominio originario pertenece al Estado.

${ }^{8}$ También se ha objetado que no puede sostenerse con acierto esta teoría porque los yacimientos minerales no son fruto del suelo bajo el que yacen, porque el derecho a los frutos o derecho de accesión es consecuencia y derivación de la propiedad de la cosa que los produce. A este respecto véase DE ARCENEGUI (2002), p. 45; MARTIN (1952), pp. 1019-1048; DIEZ PICAZO (1954), pp. 355-376.

${ }_{9}^{9}$ Según explica PUYUELO (1954), p. 6, este sistema prevaleció en el primitivo Derecho Romano y parte de la unidad entre el suelo y el subsuelo. Asimismo, fue ampliamente aplicado en países anglosajones como Inglaterra e Irlanda, Estados Unidos, Francia e Italia por solo mencionar algunos, pero como expone GONZÁLEZ (1969), p. 137, con el progreso de la industria y los cambios sociales ha venido siendo abandonado por considerarse contrario al interés de la explotación.

${ }^{10}$ Este sistema se ha aplicado, con algunas diferencias y excepciones por ejemplo en Sudáfrica, EE. UU., Gran Bretaña, Nueva Zelanda, Sri Lanka y Canadá. En otras legislaciones se aplica la accesión únicamente a ciertos minerales por ejemplo, en Argentina el artículo 2 del Código de Minería Nacional, distingue entre tres categorías de minas, en la tercera categoría se incluyen las minas que pertenecen
} 
inviable pues, llevaría a una fragmentación irracional de las explotaciones porque los yacimientos no se corresponden con la división de la propiedad de la superficie por tener ordinariamente una extensión muy superior a la de los predios y fundos suprastantes ${ }^{11}$.

\section{b) Sistema Liberal}

Para el sistema liberal, también llamado de la ocupación ${ }^{12}$ el yacimiento es considerado una res nullius, en consecuencia, pertenece a quien lo descubra y ocupe. Conforme a él, en principio las minas no son de nadie, su propietario deviene entonces por ocupación del descubridor ${ }^{13}$. Debido a los inconvenientes prácticos de su aplicación se le ha relegado a determinadas sustancias, para estimular la búsqueda y descubrimiento de yacimientos de ellas pero con ciertos matices, al descubridor no se le reconoce la propiedad de las minas sino la facultad de explotarlas con título de concesionario bajo las condiciones que establezca cada ordenamiento jurídico ${ }^{14}$.

\section{c) Sistema Regaliano o Feudal}

La descripción de este sistema cuyo surgimiento se ubica en la Edad Media, no suele ser clara en la doctrina. Por una parte, se le describe como uno que propugnaba que la propiedad de un fundo se divide y escinde en el dominio real o útil y el dominio virtual, eminente o directo. Bajo este esquema, el dominio real o útil llegaba hasta donde alcanzaba el arado, con lo cual, se limitaba al suelo; en tanto que el subsuelo constituía el dominio virtual, eminente o directo considerándose una regalía, esto es, un derecho propio del príncipe que este podía transferir por medio de concesiones.

Las minas eran consideradas regalías minoras o regalías menores, lo que implicaba considerar propiedad privada la parte efectivamente poseída por el dueño del fundo, y el subsuelo perteneciente al príncipe o al rey, en concepto del aludido dominio eminente. Otros autores entienden que, de acuerdo con este sistema, incluso en aquella época el carácter de regalía que se atribuía a las minas no venía a implicar la propiedad del príncipe ni de la Corona sino una potestad para conceder su aprovechamiento por considerarse a las minas res nullius ${ }^{15}$.

Pero, en todo caso tal y como apunta Guaita, sea que se considerasen bienes nullius o bienes del príncipe, el resultado práctico es que solo podían explotarse mediante concesión y quien las aprovechaba no se convertía en propietario sino en concesionario, carácter susceptible de perderse por infracciones tales como la falta de pago de un canon. Las minas entonces serían del rey no del Estado por un derecho de regalía ${ }^{16}$.

\section{d) Sistema Demanial o "Dominio Público"}

La teoría del dominio público (también demanio público en el derecho español, de ahí la utilización del término "demanial") en general en cuanto a institución jurídico-administrativa, como

\footnotetext{
únicamente al propietario, y que nadie puede explotar sin su consentimiento, salvo por motivos de utilidad pública. Estas comprenden ciertos tipos de rocas que abundan en la naturaleza distribuyéndose en la corteza terrestre de modo tal que prácticamente constituyen el único recurso aprovechable del suelo.

${ }^{11}$ Se considera que cuando el autor usa el término "suprastante" quiso referirse a relativo a la superficie, GUAITA (1986), p. 319.

${ }^{12}$ De acuerdo con GUAITA (1986), p. 319, también se le ha llamado sistema industrial.

${ }^{13}$ Véase también ORTIZ (1992), pp. 89 y ss.; CATALANO (1999), pp. 29-40; FRANCISKOVIC (2016), p. 145; VILDÓSOLA (1999), p. 107.

${ }^{14}$ GUAITA (1986), p. 320 y GONZÁLEZ (1969), p. 148, explican que este sistema tendría mayor aplicación en algunos Estados americanos sobre algunas sustancias específicas, o en países de formación reciente en los primeros estadios de su surgimiento.

${ }^{15}$ Para algunos autores en el sistema regalista, se distingue la propiedad existente en la superficie de la tierra de la propiedad minera (subterránea), cuyo dominio se considera originario del rey (de allí su nombre), si bien este está inhibido de explotar, y debe delegar la propiedad al primer descubridor o peticionante. PIGRETTI (1961), p. 118.

${ }^{16}$ GUAITA (1986), p. 320.
} 
se verá de inmediato, tiene como uno de sus principales antecedentes a la Revolución Francesa, reposando entre otros aspectos en la extracción de un conjunto de bienes del tráfico jurídico ordinario con el objeto de impedir su libre apropiación por los particulares. Surge como una evolución histórica (para algunos: sustitución) del sistema regalista y es el que más se ha extendido entre los países de tradición romanista.

De acuerdo a la concepción clásica de Hauriou (de notable influencia en el derecho español), el dominio público sería la propiedad de la Administración Pública que ha sido afectada formalmente a una finalidad pública y sujeta por tanto a un régimen especial ${ }^{17}$. La noción de dominio público que se ha impuesto en los países de tradición romanista comprende no solo a las minas sino también a diversas categorías heterogéneas de bienes que estarán sujetos (más bien y como se, verá "afectados") a los principios específicos que sobre ellos se establezcan en el ordenamiento jurídico, a los cuales se ha revestido fundamentalmente de los caracteres de inalienabilidad e imprescriptibilidad ${ }^{18}$. En lo que respecta a las minas, para el sistema demanial, estas son del dominio público del Estado, lo que quiere decir que este puede explotarlas directamente o ceder su explotación a terceros en las condiciones establecidas en la ley y con la calidad de concesionarios.

Entre otras cosas, lo que lo diferencia del sistema regalista es que se sustituye la titularidad del Monarca (titular de regalías) por la del Estado, lo que en opinión de algunos autores ocurriría por un principio general y abstracto de soberanía ${ }^{19}$. Para De Arcenegui esta teoría es una concepción publicista de la riqueza minera que lleva su regulación al ámbito del derecho administrativo, lo que para él supone también la transformación de la "Hacienda Patrimonialista" del antiguo régimen, en la que el Monarca se nutría de los rendimientos de determinadas categorías de bienes, como las minas con sus regalías, en una "Hacienda Tributaria" en la que los ingresos del Estado pasan de ser patrimoniales a provenir de la imposición ${ }^{20}$.

\section{e) Nacionalización}

Finalmente, es posible encontrar en la doctrina a autores que mencionan a la nacionalización como otro de los sistemas o teorías relativos a la propiedad o dominio minero. Realmente, esta en el contexto minero se relaciona por una parte con la titularidad de la mina y los yacimientos los cuales pueden pasar (todos o algunos) de ser bienes del dominio público a ser bienes patrimoniales en un ente público. Por otra parte, también con su explotación que pasaría

\footnotetext{
17 La obra de HAURIOU desarrollada en Francia en torno a la naturaleza jurídica del dominio público, como se verá ha influenciado a buena parte de los autores españoles en el área, PAREJO (2011), p. 892. Pero, siendo esta corriente la de apoyo mayoritario no es esta la única, más adelante se explicarán las distintas posiciones doctrinarias surgidas en torno al dominio público, las cuales inciden por supuesto en la noción del sistema demanial minero. Por otra parte, debe advertirse también que la noción de dominio público en el ámbito de la historia del Derecho Minero es un aspecto complejo, debatido y cuestionable, entre otras cosas porque algunos aut ores no diferencian entre el sistema regalista y el demanial, deberá leerse en contexto para inferir la posición doctrinaria respectiva. En efecto, sobre este particular de acuerdo con CATALANO (1960), p. 30, a pesar de encontrárselos ordinariamente unidos, al punto de que algunos autores latinoamericanos lo consideran como un solo sistema, los términos dominial o demanial y regalista no son sinónimos. En este trabajo se ha preferido entenderlos de forma separada porque el regalismo ha venido sufriendo modificaciones tras su incorporación en las normativas internacionales a lo largo del tiempo, incluyéndose claramente a las minas en el concepto de lo que hoy se denomina dominio público, término que sin duda ya sea que se trate de una propiedad especial del Estado o de un título de intervención de este sobre determinados bienes, comporta diferencias troncales con el regalismo nacido en la Edad Media y a su vez, forma una categoría jurídica distinta a la de los bienes patrimoniales del Estado, con lo cual, a efectos pedagógicos y analíticos se considera que resulta más sencilla su explicación a través de esta noción incluso con las deficiencias u objeciones que como se verá se aducen de esta opción.

${ }^{18} \mathrm{~A}$ pesar de que la noción de dominio público se extiende a diversas categorías heterogéneas de bienes, los cuales por tanto, gozan de situaciones y características particulares, explica GONZÁLEZ (1998), p. 48, que tanto la legislación como la doctrina se ha inclinado a una pretendida homogeneidad conceptual del dominio público, lo que hace que en ocasiones se convierta en una figura oscura y difícil de explicar, o bien en una noción en crisis porque los postulados que resulten aplicables a una categoría de bienes afecta al dominio público pueden no ser aplicables a otra que también lo esté.

${ }^{19}$ GUAITA (1986), p. 321.

${ }^{20}$ DE ARCENEGUI (2002), p. 47.
} 
normalmente de la gestión privada a la pública ${ }^{21}$. Todo lo cual suele guardar fines fiscales y motivaciones de interés público, político y/o social que aconsejen o exijan que esta actividad se encuentre íntegramente en manos del Estado ${ }^{22}$.

Pues bien, como se advertía al inicio, aunque son esas las teorías que frecuentemente se recogen en la doctrina para explicar al dominio minero, si se ha dicho que la categoría dominio minero es una especie del género dominio público, conviene hacer unas aproximaciones sobre este. Particularmente, porque con relación a la teoría general del dominio público a nivel mundial, se han formulado diversas discusiones que se han trasladado al dominio público minero. Ello obedece entre otras cosas, a que la evolución de la noción dominio público, ha venido a incorporar cada vez más categorías de bienes, que, pese a sus diferencias, se pretenden tratar con un criterio homogéneo ${ }^{23}$ lo que hace difícil explicar algunas situaciones jurídicas, como la de las minas.

\section{El debate dogmático en torno a la naturaleza del Dominio Público en el derecho comparado: ¿Manifestación del derecho de propiedad o conjunto de potestades públicas? Algunas implicaciones para el dominio minero}

Interesa en este punto hacer una breve referencia, al debate dogmático nacido en el derecho francés, trasladado al derecho español y de escaso desarrollo en América Latina y en Chile, en el que se plantea si el dominio público es una manifestación del derecho propiedad del Estado o si se trata de un conjunto de potestades públicas ${ }^{24}$. Con las limitaciones del caso (por exceder al

\footnotetext{
${ }^{21}$ DE ARCENEGUI (2002), p. 48.

22 GUAITA (1986), p. 321. Como ejemplos de procesos de nacionalización ocurridos en la minería iberoamericana pueden mencionarse nacionalización de las minas en Bolivia (1952), la nacionalización de la gran minería del cobre en Chile (1971), y más recientemente la nacionalización del oro en Venezuela (2011). En el contexto de lo que fue la Revolución Nacional boliviana, tuvo lugar la nacionalización de la minas como uno de sus hitos más relevantes. El 31 de octubre de 1952, en Catavi (Potosí), el entonces presidente Víctor Paz Estenssoro, junto con su Ministro de Minas, Juan Lechin Oquendo, firmaron el decreto de nacionalización traspasando los bienes de las 163 minas distribuidas en 13 compañías mineras de Patiño, Hoschild y Aramayo a la recientemente creada mediante Decreto Supremo 31196 del 2 de octubre de 1952, "Corporación Minera de Bolivia", empresa encargada de administrar la cadena productiva de la minería estatal en el país. Sobre este particular léase el trabajo de MANSILLA (1980), pp. 117-128. En Chile, la nacionalización del cobre fue producto de las políticas públicas iniciadas en 1953 en la presidencia de Carlos Ibáñez, proceso que requirió la reforma de la Constitución Política de 1925, concretándose en 1971 con la Ley 17.450, de reforma constitucional, durante la presidencia de Salvador Allende. Al respecto, véase: MAIRA (1970), pp. 29-30; INGRAM (1974); y MELLER (1996). En Venezuela, de acuerdo con el Decreto con rango, valor y fuerza de Ley Orgánica que reserva al Estado las actividades de exploración y explotación del oro, así como las conexas y auxiliares a estas, del año 2014 y derogado en 2015, se reservó al Estado la exploración y explotación del oro y "otros minerales estratégicos," es decir, aquellos que sean considerados de conveniencia nacional y de interés público, declarados como tal mediante Decreto dictado por el Ejecutivo Nacional. En todo caso, tanto la minería como la industria petrolera han sufrido varias transformaciones, pero la nacionalización no es extraña a la historia de Venezuela, otro ejemplo notable de esto es que en el año 1976 ya se había nacionalizado la industria petrolera, si bien en 1990 con la caída de los precios del petróleo se vivió una real "apertura petrolera" como mét odo para atraer las inversiones extranjeras, pero entre los años 1999 y 2007 con el gobierno de Hugo Chávez esto fue cambiando progresivamente una política tendiente a controlar la oferta de petróleo y a recuperar de la renta petrolera mediante el establecimiento de un margen mínimo de participación del Estado en los proyectos hidrocarburíferos y a través del incremento de regalías. Al respecto ver: CORONE $L$ (1983) y HONORIO (2011), pp. 7-15.

${ }^{23}$ Se comparte aquí la opinión de GONZÁLEZ (1998), pp. 34-61, para quien resulta inadecuado pretender tratar de forma homogénea a las distintas categorías que integran en la actualidad la noción de dominio público en el derecho español.

${ }^{24}$ GONZÁLEZ (1998), pp. 34-61, hace un resumen de lo que denomina "la polémica doctrinal sobre la naturaleza del dominio público," en el que se pregunta ¿qué es el dominio público?, ¿nos encontramos ante una manifestación del derecho de propiedad, o, por el contrario, es un título de intervención de los poderes públicos sobre determinados bienes? Según explica NIETO (1987), p. 14, la polémica sobre el título jurídico que relaciona a los bienes de dominio público con sus titulares es tan antigua como la propia existencia de tal dominio, habiendo dado lugar siempre y en todos los países a posiciones contrapuestas, que se han defendido con apasionamiento en uno de los torneos dogmáticos más persistentes de la cultura jurídica europea: HAURIOU contra PROUDHON en Francia, IHERING Y KELLER cont ra RÜTTIMANN Y DERENBURG en Alemania. Más adelante se hará referencia a algunos elementos de este debate en el derecho francés por ser el que más ha influenciado la cultura jurídica española y de los países de tradición romanista. En todo caso, en lo que respecta al derecho alemán, explica GONZÁLEZ (2009), p. 71, nota 10, que la controversia sobre el carácter de las cosas públicas adquirió en Alemania un nivel dogmático insuperable con ocasión del pleito sobre las murallas desafectadas en Basilea en el año 1862, en él se discutían los
} 
propósito de esta investigación), es importante mencionar algunos elementos de esta discusión para asociarlos al contexto de la actividad minera, porque de alguna forma sus presupuestos se han trasladado al régimen de las minas y como se explicará más adelante, en buena medida ha sido incorporada a los escasos estudios que analizan científicamente el dominio minero chileno como una categoría integrada al dominio público.

La presencia de vestigios de viejas concepciones sobre el dominio público en la bibliografía chilena que intenta explicar al dominio minero, así como la dificultad de entender ciertos planteamientos en ella formulados, obliga a hacer algunas precisiones sobre las bases y esencia del dominio público y su evolución histórica, para explicar lo que en definitiva es el dominio público en el contexto actual y luego dentro de él, el dominio minero ${ }^{25}$.

Como se apuntaba, con el término dominio público (llamado también "demanio" en el derecho español), se designa a algunos bienes cuya titularidad es del Estado y por esa razón, están sujetos a un régimen especial inspirado generalmente por los principios de inalienabilidad, imprescriptibilidad e inembargabilidad. Pero esto que parece tan sencillo de explicar, no lo es tanto al enfrentarse con las opiniones doctrinales que son por demás diversas y complejas.

Aunque para Parejo Alfonso ${ }^{26}$ toda reconsideración del dominio público ha de tener en cuenta $y$, al propio tiempo, clarificar los componentes de arrastre histórico que aún continúan perturbando la categoría (tarea que no resulta sencilla, pues los orígenes de la misma se entremezclan con postulados romanos, medievales, revolucionarios y postrevolucionarios, hasta llegar a la actualidad), se prescinde del análisis pormenorizado de dichos hitos por exceder al propósito de esta investigación ${ }^{27}$, que en este punto tiene como finalidad mostrar sus bases y cómo fue produciéndose la evolución del mismo, de forma tal que ello sirva de herramienta para aproximar o facilitar la compresión de lo que hoy en día sea la naturaleza del dominio público, para llegar a la del dominio minero.

Pero, pese a considerar necesaria la breve revisión de esta evolución histórico-jurídica por su influencia en el desarrollo de la categoría, no debe perderse de vista que dichos hitos surgieron en un momento histórico, político y jurídico determinado. De tal suerte que en el contexto de esta investigación, concordando con lo expuesto por Vergara Blanco, la única respuesta que podría proporcionar la historia es que la explicación de la naturaleza jurídica del dominio público o sea, este vínculo jurídico que el Estado se ha procurado con algunos bienes (especialmente las minas), ha de buscarse con las actuales tareas de1 Estado y en su forma de llevarlas a cabo, las cuales hoy

solares la ciudad y el cantón. Formaron parte de aquel asunto los pandectistas de la época, RÜTTIMANN Y DERENBUR quienes sostenían la existencia de un derecho de propiedad, aunque este fuera de uso común (Gemeingebrauch an privateigentum); mientras que IHERING Y KELLER sostenían lo contrario. En tanto que en la tradición jurídica alemana seguía la primera postura.

${ }^{25}$ Es necesario precisar que lo que sigue no es una descripción histórica y minuciosa de la evolución del tratamiento jurídico que se ha dado a las minas. Para ello es imprescindible acudir a la obra de VERGARA (1992), con él en este trabajo entendemos que, aunque las minas han pasado por diversos regímenes a lo largo de los siglos (siendo consideradas en ocasiones bienes patrimoniales y en otras, bienes de dominio público), hoy en día están integradas al dominio público. En consecuencia, lo que pretende esta investigadora es explicar algunas de las implicaciones de su inclusión en el dominio público y la forma en la que ciertos elementos de debate de esa categoría macro - que para otros autores no debería ser aplicada a las minas por ejemplo en España GONZÁLEZ (1998), p. 31- han dificultado la comprensión de la relación que existe hoy en día entre el Estado y las minas.

${ }^{26}$ PAREJO (1983), p. 2383. En ese sentido, para el autor en la posterior evolución histórica de la figura, han sido tres las instituciones romanas influyentes: a) la clasificación y el régimen de las cosas; b) el régimen del territorio "ager publicus» perteneciente al pueblo romano y; c) El régimen de los bienes del «princeps»; por otra parte, debe ser objeto de análisis seguidamente, d) la regalía como institución esencial del Derecho Medieval, así como e) la Revolución Francesa y el nacimiento de la Administración contemporánea.

${ }^{27}$ En este orden de ideas para profundizar al respecto, resulta imprescindible la lectura de la obra de VERGARA (1992), quien realiza un análisis detallado de los aspectos históricos y jurídicos del dominio público y el dominio minero. Al respecto resulta indispensable también la obra de VEGTING (S/A). 
en día son distintas a lo que ocurría en otrora ${ }^{28}$. Se partirá entonces por el hito más relevante el domaine public francés.

\subsection{El domaine public francés. Teorías sobre la naturaleza del dominio público}

La teoría del dominio público cuyo origen es doctrinal y ha pasado por momentos de verdadera "crisis" 29 , llegando a cuestionarse la necesidad de su existencia misma (aunque para algunos goce hoy de una envidiable salud) ${ }^{30}$, se ha planteado como una cuestión central la de su naturaleza jurídica, ¿en qué consiste esa titularidad del Estado? ¿Qué es el dominio público? ¿Es una manifestación del derecho de propiedad del Estado o un título de intervención sobre determinados bienes? La respuesta a ello puede variar según el ordenamiento jurídico respectivo, pudiendo llegarse a conclusiones diferentes.

Sin embargo, entre aquellos de corte romanista los planteamientos doctrinarios han tenido (con ciertos matices) la importante influencia del debate que al efecto se llevó en cuanto al domaine public francés ${ }^{31}$. Es aceptado en la doctrina administrativista que a pesar de las influencias del derecho romano y el derecho medieval, la noción actual de dominio público tiene como su momento más importante ${ }^{32}$ el Decreto de la Asamblea Nacional de 22 de noviembre-1 de diciembre de 1790 "relatif aux domaines nationaux, aux échanges et, concessions et aux apanages". En él se establece que todas las porciones de territorio nacional que no son susceptibles de propiedad privada se consideran de dominio público. Asimismo que, el dominio nacional se extiende a todas las propiedades inmuebles y a todos los derechos reales que pertenecen a la nación. ${ }^{33}$ Desde ese entonces se desarrolla la doctrina del dominio público y la controversia sobre su naturaleza jurídica a la cual se hace referencia ${ }^{34}$.

Es aquí cuando la doctrina francesa comienza a preguntarse si los bienes que integran la noción de dominio público están sujetos a un derecho real de propiedad (en el sentido civil de este término) o si están revestidos de una naturaleza diferente, propia y específica del derecho administrativo. Para entender la cuestión, es preciso mencionar que en la doctrina prerevolucionaria no existía la distinción que hoy se tiene entre dominio público y privado, lo que sí existía en la Francia de aquel entonces, era una "regla de inalienabilidad" del dominio real que conforme al Edicto de Moulins de 1566 incluía todos los bienes de la Corona sin distinción. Aquí esa

\footnotetext{
28 VERGARA (1989), p. 31.

${ }^{29}$ GONZÁLEZ-BERENGUER (1968), pp. 191-220.

${ }^{30}$ CASINO (2009), p. 98.

${ }^{31}$ GONZÁLEZ (1998), p. 35. De igual forma, apunta VERGARA (1989), p. 29, que es comúnmente aceptado en la doctrina administrativista que la teoría del dominio público es una creación originaria del derecho público francés. Para PAREJO (1983), p. 2391, con la Revolución Francesa tiene lugar una depuración técnica del concepto de dominio público, aunque fuertemente lastrada por toda la evolución anterior. Según explica TRAORÉ (2008), p. 13, la noción de dominio público fue el resultado de una transformación progresiva del estatuto jurídico de las propiedades públicas, siendo una creación de la ciencia jurídica francesa que durante mucho tiempo, en ausencia de textos legislativos habían elaborado una teoría a partir de la concepción civilista de la propiedad privada prevista en el Código Civil. Explica el citado autor, que GASTÓN JÉZE, podría ser quien en 1944 advirtió sobre ello, notando que ese trabajo doctrinal se había fundado a partir de la constatación según la cual la expresión "dominio público" se utiliza en el texto del Código Civil para designar ciertas categorías de bienes pertenecientes al Estado o a otras autoridades públicas. Sin embargo, esta categoría jurídica no fue acompañada por ninguna regla especial.

Así, la teoría del dominio público, de origen doctrinal, teniendo una vocación de elaborar el régimen especial antes de hacerse aplicable a la categoría de dominio público, identificada por el legislador (el artículo 538 del Código Civil que contendría la clasificación de bienes públicos que no son susceptibles de propiedad privada) pudo beneficiarse de una transposición que le permitió asimilar, - -según la palabra de GASTÓN JÉZE-, el dominio público a un régimen de propiedad.

32 MENÉNDEZ (2016), p. 209; CHEMÁS (2015), p. 225; DARNACULLETA (2000), p. 35; MARTíNEZ (2000), p. 265; FRANCH (1996), p. 421; BARCELONA (1995), p. 549.

${ }^{33}$ Lo que posteriormente es recogido por el Código Civil de 1804

${ }^{34}$ GONZÁLEZ (1998), p. 36; PAREJO (1983), p. 2391
} 
prohibición de enajenar se basa en la inexistencia de un derecho de propiedad sobre dichos bienes por parte de la monarquía ${ }^{35}$.

A partir del mencionado Decreto de 22 de noviembre contentivo del "Código del Dominio Público", se emplea la expresión "dominio público" como sinónimo de dominio nacional, esto es, aquel perteneciente al Poder Público, pero, sin distinguir lo que sería el dominio público del privado $^{36}$. De ahí que en la doctrina se suela diferenciar entre las teorías antes y después de la codificación.

Se atribuye a Pardessus la separación por primera vez de "propiedad" y "dominio público" al expresar en el año 1806 en su Traité des servitudes ou fonciers que "el Estado no es el propietario, sino que es el depositario y conservador de los bienes" ${ }^{37}$. Pero en la misma línea de pensamiento, es Proudhon ${ }^{38}$ quien (partiendo de las ideas de Pardessus, Toullier, Delvincourt y Duranton) da fuerza a una teoría que dominaría buena parte del siglo XIX, contenida en su Traité du domaine public ou de la distinction des biens, en el que diferenció dominio público y dominio privado del Estado, afirmando respecto de los bienes que integran el primero, que el Estado tiene poderes de guardia y vigilancia, pero que no mantiene una auténtica posición de titular dominical (propietario en términos del Código Civil) respecto de dichos bienes.

El dominio público sería, por tanto, una potestad pública y no una relación dominical propiamente dicha. Lo cual era ampliamente aceptado tanto por civilistas como por administrativistas de la época ${ }^{39}$.

Para Proudhon, la relación demanial supondría un poder especialmente encargado de dirigir y administrar las cosas que han sido, por las leyes, afectadas al uso de todos y sobre las cuales no cabe propiedad de ninguno. El dominio público, es un dominio eminente, una especie de soberanía sobre tales bienes, que se distinguiría de la propiedad porque mientras el dominio de propiedad es un dominio de aprovechamiento directo para su dueño, el dominio público, para el Gobierno-Estado no es más que un dominio de protección, para garantizar el aprovechamiento por parte de todos los individuos que puedan precisarlo ${ }^{40}$.

Por eso Proudhon distingue entre tres clases de bienes: las cosas comunes (aire, luz, mar y agua), las cosas privadas (esto es apropiables de forma pública o privada, tales como prados, edificios, frutos y muebles) y finalmente, las cosas públicas que conforman efectivamente la categoría de dominio público. Lo que en definitiva se refiere a bienes que han sido puestos por la autoridad pública fuera de toda posesión privada: ellos son los puertos de mar, las carreteras, los caminos públicos de toda clase, las murallas de las plazas militares, los ríos y riberas navegables, los

\footnotetext{
${ }^{35} \mathrm{El}$ artículo segundo de este documento declaró que el dominio real (definido como toda la tierra controlada por la corona durante más de diez años) no podía enajenarse, excepto en dos casos: con vinculaciones, en el caso de una emergencia financiera, con una opción perpetua de recomprar la tierra; y para formar un infantazgo, que deben regresar a la corona en su estado original cuando se extinguiera la línea masculina. Sobre el significado y las consecuencias de esta regla de inalienabilidad ver DUFAU (1977), pp. 195-200.

${ }^{36}$ VERGARA (1998), p. 309.

${ }^{37}$ PARDESSUS (1811), pp. 56-85. La doctrina administrativista reconoce al citado autor como el primero en separar las nociones propiedad y dominio público en su Tratado publicado en el año 1806, para esta investigación se ha tenido acceso a la referida obra, en su edición publicada en el año 1811, en la que el autor distingue entre el dominio público (inalienable, imprescriptible, no susceptible de servidumbre y consagrado por naturaleza al uso de todos y al servicio general) y el dominio nacional compuesto por bienes susceptibles de apropiación privada, enajenables de acuerdo con las formalidades establecidas por las leyes, prescriptibles y productores de ingresos. ${ }^{38}$ PROUDHON (1843), pp. 238-276.

39 BRARD (1994), p. 5. De acuerdo con VEGTING (S/A), p. 195, no solo los autores que se ocuparon del derecho administrativo siguieron a PROUDHON, sino también los civilistas. Sus opiniones fueron aceptándose poco a poco por la jurisprudencia, hasta que finalmente esta teoría fue reconocida legalmente a tal punto que fue incluida en las leyes relativas a la propiedad en los territorios coloniales.

40 PROUDHON (1839), p. 86.
} 
canales de navegación interior, etc. En todo caso, la consideración de esta última categoría de bienes tendría un carácter restrictivo ${ }^{41}$.

Con la evolución de la doctrina francesa y la llegada de la codificación, a esta posición viene a contraponerse la tesis de Hauriou ${ }^{42}$ quien sostiene que el dominio público es una manifestación del derecho de propiedad. Se trataría de alguna sujeta a ciertas peculiaridades eso sí. Para Hauriou si bien la institución aplicable es la propiedad, nunca podría ser entendida en los mismos términos de la propiedad ordinaria.

De acuerdo con esta tesis, las peculiaridades vienen dadas no tanto de la condición pública de su titular como de las características de su función pública o de utilización especial. Los bienes que integran el dominio público constituirían una especie de "propiedad administrativa" que recae sobre determinadas cosas, las cuales son sometidas a un régimen jurídico exorbitante por razones de interés general, pero, no obstante ello, es una propiedad auténtica e inequívoca ${ }^{43}$.

Como se indicó anteriormente, conforme al autor en comento, el dominio público es la propiedad de la Administración Pública que ha sido "afectada" formalmente a una finalidad pública y sujeta por tanto a un régimen especial. La "afectación" es entonces el centro de su teoría, conforme a la cual, las propiedades administrativas son afectadas a la utilidad pública y como consecuencia de ello son sometidas a un régimen especial de utilización y protección, criterio que se extendió a las cosas afectadas a un servicio público ${ }^{44}$.

Esta noción es la que se ha impuesto en los países de tradición romanista, en los que se han incluido diversas categorías heterogéneas de bienes, que por distintos criterios se someten a los principios específicos que sobre ellos se establezcan en el ordenamiento jurídico, a los cuales se ha revestido fundamentalmente de los caracteres de inalienabilidad e imprescriptibilidad. Porque, aunque el Estado puede ser titular de bienes en propiedad civil perfecta (en términos del Código Civil), el dominio público vendría a suponer una propiedad especial sometida por tanto a un tratamiento distinto de aquella ${ }^{45}$.

En la tesis de Hauriou (quien debate con Duguit ${ }^{46}$ sobre la naturaleza del dominio público), el dominio público es un derecho de propiedad que por ser atribuido a una Administración Pública presenta unos caracteres particulares en atención a la finalidad pública que afecta a los bienes que lo componen. De ahí que, estos serían susceptibles de apropiación (no en su conjunto, pero sí en porciones); y que respecto de todos ellos se pueda ejercer la acción reivindicatoria que es la que corresponde en esencia al propietario ${ }^{47}$.

Asimismo, para explicar que aun siendo propiedad del Estado estén sometidos a las reglas de inalienabilidad e imprescriptibilidad (aspectos fundamentales históricamente utilizados para explicar las características de la categoría), señala que se trata de reglas exorbitantes o excepciones al derecho de propiedad, que encuentran su justificación precisamente en el interés público inmerso; pero que ello no es suficiente ni contradice la existencia de una relación de propiedad entre la Administración y los bienes de dominio público. En efecto, para el dominio público la

\footnotetext{
${ }^{41}$ BRARD (1994), p. 6.

${ }^{42}$ HAURIOU (1897), pp. 613-681.

43 GONZÁLEZ (1998), p. 35. Esta influencia se observa por ejemplo en el derecho español de los bienes públicos en el que ha sido particularmente importante la obra de HAURIOU introducida en el país a través de FERNÁNDEZ DE VELASCO.

${ }^{44}$ CAZORLA (1983), p. 316.

${ }^{45}$ Esta diferencia era un tanto más sencilla de observar en el nacimiento de estas teorías, sin embargo, en la actualidad, la noción de dominio público integra tantos bienes que son pocos aquellos que puedan considerarse del "dominio privado" del Estado, GORDILLO (2014), p. 355.

${ }^{46}$ DUGUIT (1930), pp. 320-385.

47 SERNA (2009), p. 51.
} 
inalienabilidad se limitaría a la necesidad de una decisión previa o autorización que justifique enajenar el bien.

Por su parte, para Duguit ${ }^{48}$ los bienes del dominio público no son susceptibles de propiedad ni pública ni privada. En ese sentido, a decir del autor, el Estado tendría con ellos un deber de protección y de garantía de su afectación al uso público, pero no un derecho de propiedad. De manera que el régimen aplicable a los mismos es un régimen de derecho público, distinto al régimen de propiedad que es de derecho privado.

\subsection{Recepción de la teoría del dominio público en el derecho español}

En España la situación doctrinaria se desarrolló en términos similares a lo ocurrido en Francia. En ese sentido, durante las primeras décadas del siglo XX, la tesis de Proudhon introducida en el país por Colmeiro ${ }^{49}$ es ampliamente aceptada; hasta que Fernández de Velasco ${ }^{50}$ dio a conocer la obra de Hauriou, opinando que el dominio público es fundamentalmente una forma de propiedad exorbitante, inalienable e imprescriptible; y que su esencia radica en la afectación o destino de determinados bienes a la utilidad pública. Esta nueva tesis influenció la opinión de autores como Álvarez-Gendín, Guaita, García de Enterría y Garrido Falla ${ }^{51}$, quienes ven en el dominio público una propiedad especial de la Administración. Algún autor llegaría incluso a afirmar la unanimidad de aceptación de esta tesis del dominio público como una relación de propiedad ${ }^{52}$.

No obstante, más recientemente, otro sector representado por autores como Villar Palasí, Parejo Gamir y Rodríguez Oliver, Gallego Anabitarte, Parejo Alfonso ${ }^{53}$ defiende la idea de que el dominio público no es sino un título de intervención administrativa, dirigido a proteger y ordenar la utilización de determinados bienes de interés general. En la misma línea se encuentra, González García $^{54}$ para quien el Estado (por medio de las Administraciones Públicas) es titular de competencias y funciones sobre los bienes que integran el dominio público ${ }^{55}$.

De todo lo dicho se sigue que, desde el punto de vista dogmático, el dominio público comporta enormes dificultades para su explicación, por lo que es una de las instituciones más debatidas en el Derecho Administrativo; situación que se torna aún más confusa cuando sobre la base de una sola teoría se pretenden explicar las diversas clasificaciones que lo integran. También, cuando se pretenden aplicar sin mayor análisis las instituciones que, aunque sirvieron de base para el nacimiento de la categoría, no podrían ser enteramente aplicables al contexto actual porque en aquel entonces, no se conocían conceptos como las potestades administrativas, la competencia y sus límites a través del principio de legalidad administrativa del Estado de Derecho, por solo mencionar alguno ${ }^{56}$.

\footnotetext{
${ }^{48}$ DUGUIT (1930), pp. 320-385.

${ }^{49}$ COLMEIRO (1850). De acuerdo con SERNA (2009), p. 52, Manuel Colmeiro es el primer autor español en el que se percibe la influencia de las teorías de PROUDHON. El autor distingue entre dominio público y dominio del Estado, y considera que los bienes del dominio público corresponden a la Nación por el derecho de soberanía, mientras que el patrimonio del Estado se fundamenta en un derecho de propiedad.

${ }^{50}$ FERNÁNDEZ DE VELASCO (1921), pp. 230-236.

${ }^{51}$ ÁLVAREZ-GENDÍN (1956), pp. 259-302; GUAITA (1956), pp. 121-140 y GUAITA (1986); GARCÍA DE ENTERRÍA (1984-1985), GARCÍA DE ENTERRÍA (1998) y GARCÍA DE ENTERRÍA (1982); GARCÍA DE ENTERRÍA Y ESCALANTE (1982); GARRIDO (2002), y GARRIDO (1962), pp. 303340.

52 CAZORLA (1983), p. 316

53 VILLAR (1964) Y VILLAR (1968); PAREJO (1975); PAREJO Y RODRÍGUEZ (1976); GALLEGO (1982), pp. 227-309, y GALLEGO (1983), pp. 13420; PAREJO (1983), pp. 2379-2422.

${ }^{54}$ GONZÁLEZ (1998) Y GONZÁLEZ (2009), pp. 67-108.

${ }^{55}$ Para ampliar léase SERNA (2009), pp. 39-66.

${ }^{56}$ VERGARA (1990), p. 136.
} 


\subsubsection{Situación actual del dominio público en el derecho español}

Con todo, al margen de las discusiones doctrinarias descritas anteriormente, en la actualidad, la Constitución Española de 197857, establece las bases del dominio público vigentes en tal ordenamiento, cuando en su artículo 132.1, dispone que corresponde a la ley regular el régimen jurídico de los bienes de dominio público y de los comunales, debiendo inspirarse en todo caso, en los principios de inalienabilidad, imprescriptibilidad e inembargabilidad, así como su desafectación. Asimismo, en virtud del numeral 2 del artículo en comento, serán bienes de dominio público estatal los que determine la ley y, en todo caso, la zona marítimo-terrestre, las playas, el mar territorial y los recursos naturales de la zona económica y la plataforma continental.

La ley en cuestión es en la actualidad la Ley del Patrimonio de las Administraciones Públicas ${ }^{58}$, de acuerdo con la cual "el patrimonio de las Administraciones Públicas está constituido por el conjunto de sus bienes y derechos, cualquiera que sea su naturaleza y el título de su adquisición o aquel en virtud del cual les hayan sido atribuidos" (Artículo 3.1).

Adicionalmente, el citado instrumento aclara que según se establece en el artículo 4 ejusdem, por razón del régimen jurídico al que están sujetos, los bienes y derechos que integran el patrimonio de las Administraciones Públicas pueden ser de dominio público o demaniales y de dominio privado o patrimoniales. En tanto que son bienes y derechos de dominio público los que, siendo de titularidad pública, se encuentren afectados al uso general o al servicio público, así como aquellos a los que una ley otorgue expresamente el carácter de demaniales (Artículo 5) ${ }^{59}$.

Por argumento en contrario, son bienes y derechos de dominio privado, o patrimoniales, los que siendo de titularidad de las Administraciones Públicas, no tengan el carácter de demaniales ${ }^{60}$. De igual forma, en una tendencia patrimonializadora ${ }^{61}$, derivada de la gran influencia que como ha podido verse ha tenido la teoría de Hauriou y su posterior desarrollo en España ${ }^{62}$, se establecen en el artículo 6, los principios aplicables a los bienes y derechos de dominio público siguientes:

a) Inalienabilidad, inembargabilidad e imprescriptibilidad.

b) Adecuación y suficiencia de los bienes para servir al uso general o al servicio público a que estén destinados.

c) Aplicación efectiva al uso general o al servicio público, sin más excepciones que las derivadas de razones de interés público debidamente justificadas.

d) Dedicación preferente al uso común frente a su uso privativo.

\footnotetext{
${ }^{57}$ Boletín Oficial del Estado Número 311, de 1978.

${ }^{58}$ Ley 33/2003, de 2003.

59 El numeral 3, del artículo en comento extiende la noción de bienes de dominio público a los inmuebles de titularidad de la Administración General del Estado o de los organismos públicos vinculados a ella o dependientes de la misma en que se alojen servicios, oficinas o dependencias de sus órganos o de los órganos constitucionales del Estado. De igual forma, se aclara en el numeral 4 que los bienes y derechos de dominio público se regirán por las leyes y disposiciones especiales que les sean de aplicación y, a falta de normas especiales, por esa misma ley y las disposiciones que la desarrollen o complementen. Siendo que las normas generales del derecho administrativo y, en su defecto, las normas del derecho privado, se aplicarán como derecho supletorio.

60 Para PAREJO et al. (2009), p. 65. Las normas citadas suponen la combinación de las perspectivas subjetivas (titularidad de una Administración Pública) y objetivas (afectación a una función pública y consecuente régimen jurídico específico) para categor izar a los bienes públicos. De esta forma, si bien la Administración ostenta siempre la titularidad de los bienes y derechos integrantes de su patrimonio, la de los demaniales se califica simplemente de pública, refiriendo a un régimen de gestión y administración que reposa en principios propios derivados de la afectación y son opuestos a los de la propiedad privada; en el caso de los patrimoniales, se habla de titularidad de las Administraciones, que aunque refiere primariamente a un régimen jurídico-público establecido en la ley en cuestión, puede ser compatible con los que informan la propiedad privada.

${ }^{61}$ PAREJO et al. (2009), p. 64.

62 En la doctrina jurídico-administrativa actual sigue siendo relevante la visión del dominio público inspirada en el derecho francés, fundamentalmente gracias a la autoridad de GARCÍA DE ENTERRÍA Y SAINZ MORENO.
} 
e) Ejercicio diligente de las prerrogativas que la presente ley u otras especiales otorguen a las Administraciones públicas, garantizando su conservación e integridad.

f) Identificación y control a través de inventarios o registros adecuados.

g) Cooperación y colaboración entre las Administraciones Públicas en el ejercicio de sus competencias sobre el dominio público.

Con la consagración de estos principios se instaura pues, en primer lugar, la indisponibilidad de los bienes demaniales, para protegerlos de todo acto consciente o inconsciente, directo o indirecto que suponga la libre adquisición del bien por los particulares. La inalienabilidad como se ha visto es uno de los elementos más característicos del dominio público e implica que los bienes mientras estén sujetos a él no pueden ser enajenados, precisamente por estar estos fuera del comercio. Conforme a esta regla tampoco pueden ser objeto de expropiación forzosa.

Sin perjuicio de la posibilidad de su desafectación ${ }^{63}$ (en la medida en que esta sea posible), en virtud de la cual recuperarían su enajenabilidad. La inalienabilidad tampoco impide las mutaciones demaniales ${ }^{64}$, el otorgamiento de concesiones, ni la transferencia de bienes a otros entes públicos producto de traspaso de competencias o de servicios ${ }^{65}$. La inembargabilidad por su parte, evita la posibilidad de que se dicten embargos contra los bienes demaniales ${ }^{66}$.

Otra consecuencia de la sustracción de los bienes demaniales del comercio es que estos no pueden ser objeto de prescripción adquisitiva por parte de los particulares, tampoco se perderá el carácter público del bien por el transcurso del tiempo. De ahí su imprescriptibilidad. En todo caso, el sometimiento de ciertos bienes al dominio público implica que deben ser destinados a un uso general o al servicio público, de forma tal que la desafectación a esos destinos debe justificarse en razones de interés público, de ahí que se prefiera el uso común al uso privativo.

En ese sentido, el artículo 85 de la Ley del Patrimonio de las Administraciones Públicas, establece en su numeral 1, que se considera uso común de los bienes sujetos al dominio público, aquel que corresponde por igual y de forma indistinta a todos los ciudadanos, así pues, el uso que hagan unos, no impide el uso de los demás interesados. Por otra parte, conforme al numeral 2, es uso que implica un aprovechamiento especial del dominio público el que, sin impedir el uso común, supone la concurrencia de circunstancias tales como la peligrosidad o intensidad del mismo, preferencia en casos de escasez, la obtención de una rentabilidad singular u otras semejantes, que determinan un exceso de utilización sobre el uso que corresponde a todos o un menoscabo de este. Finalmente, según lo previsto en el numeral 3, habrá uso privativo cuando existe ocupación de una porción del dominio público, de modo que se limita o excluye la utilización de este por otros interesados.

\footnotetext{
${ }^{63}$ La afectación supone que el bien o derecho demanial están vinculados a un uso o servicio público, con la finalidad de que el bien en cuestión pueda prestar un servicio más adecuado a los intereses generales. La desafectación es entonces el fenómeno contrario. Es decir, la salida del bien o derecho del régimen de afectación, el bien deja de estar destinado al cumplimiento de un uso general o un servicio público perdiendo su condición demanial, lo que generalmente ocurre mediante un acto administrativo o judicial. La consecuencia de esto es que en algunos casos el bien pasa a ser patrimonial y en otros, privado.

${ }^{64}$ Las mutaciones demaniales suponen modificaciones en la finalidad y/o en el sujeto al que están afectados los bienes de dominio público, sin que por ello se altere su carácter demanial.

${ }^{65}$ GONZÁLEZ (2009), p. 80.

66 De acuerdo con GONZÁLEZ (2009), p. 82, la regla de inembargabilidad está extendida a todos los bienes públicos, pero desde la Sentencia del Tribunal Constitucional Español N 166/1998, de 15 de julio, han quedado limitados sus efectos únicamente a los bienes del dominio público o a los bienes patrimoniales materialmente afectos a un uso o servicio público, tal y como se dispone en el artículo 23 de la Ley 47/2003, de 26 de noviembre, General Presupuestaria, que al efecto establece que: "ningún tribunal ni autoridad administrativa podrá dictar providencia de embargo ni despachar mandamiento de ejecución contra los bienes y derechos patrimoniales cuando se encuentren materialmente afectados a un servicio público o a una función pública, cuando sus rendimientos o el producto de su enajenación estén legalmente afectados a fines diversos, o cuando se trate de valores o títulos representativos del capital de sociedades estatales que ejecuten políticas públicas o presten servicios de interés económico general”.
} 
En este orden de ideas, el artículo 86 ejusdem, establece los títulos habilitantes para el uso de los bienes del dominio público. En ese sentido, el uso común podrá realizarse libremente, sin más limitaciones que las derivadas de su naturaleza, lo establecido en los actos de afectación o adscripción, y en las disposiciones que sean de aplicación. Por su parte, el aprovechamiento especial de los bienes de dominio público, así como su uso privativo, cuando la ocupación se efectúe únicamente con instalaciones desmontables o bienes muebles, estarán sujetos a autorización o, si la duración del aprovechamiento o uso excede de cuatro años, a concesión. En tanto que, el uso privativo de los bienes de dominio público que determine su ocupación con obras o instalaciones fijas (por ejemplo, las minas) deberá estar amparado por la correspondiente concesión administrativa.

\subsubsection{Situación actual del dominio minero en el derecho español}

En el contexto de la actividad minera, según lo establece el artículo 2.1 de la Ley de Minas ${ }^{67}$, estas tienen carácter demanial, y en virtud de lo dispuesto en el artículo 3.1. ejusdem, se clasifica a los yacimientos minerales y demás recursos geológicos en las siguientes secciones:

A) Pertenecen a la misma los de escaso valor económico y comercialización geográficamente restringida, así como aquellos cuyo aprovechamiento único sea el de obtener fragmentos de tamaño y forma apropiados para su utilización directa en obras de infraestructura, construcción y otros usos que no exigen más operaciones que las de arranque, quebrantado y calibrado.

B) Incluye, con arreglo a las definiciones que establece el Capítulo Primero del Título IV, las aguas minerales, las termales, las estructuras subterráneas y los yacimientos formados como consecuencia de operaciones reguladas por esta Ley.

C) Comprende esta sección cuantos yacimientos minerales y recursos geológicos no estén incluidos en las anteriores y sean objeto de aprovechamiento conforme a esta Ley ${ }^{68}$.

D) Los carbones, los minerales radiactivos, los recursos geotérmicos, las rocas bituminosas y cualesquiera otros yacimientos minerales o recursos geológicos de interés energético que el Gobierno acuerde incluir en esta sección, a propuesta del Ministro de Industria y Energía, previo informe del Instituto Geológico y Minero de España.

La ratificación de su carácter demanial y la separación por secciones de los recursos minerales, hacen que su aprovechamiento esté sujeto a normas especiales que varían conforme a cada categoría, pero que en todo caso suponen algún tipo de actividad de la Administración. Así, para el aprovechamiento de los recursos pertenecientes a la sección A, deberá obtenerse, previamente a la iniciación de los trabajos, la oportuna Autorización de Explotación de la Delegación Provincial correspondiente del Ministerio de Industria, conforme a lo establecido en los artículos 16 al 22 de la ley en comento.

Para los recursos que integran la sección $B$, se requerirá también una Autorización, en este caso de Aprovechamiento, la cual puede acordarse de oficio o a solicitud de parte y en caso de cumplirse los extremos de ley, se acordará mediante resolución del Ministerio de Industria, a

\footnotetext{
${ }^{67}$ Ley 22/1973, de 21 de julio, modificada por la Ley 54/1980, de 5 de noviembre.

${ }^{68}$ Debe advertirse que la 1973, producto de la modificación se excluyó de la sección C del artículo 3 en su versión original, y se creó una nueva sección, denominada $D$; de igual forma, se consideró aplicables a la sección $D$ los preceptos de la Ley de Fomento de la Minería referidos a la sección C. En su disposición final 2a estableció: "El Gobierno, en el plazo de un año, remitirá a las Cortes Generales un proyecto de Ley de modificación del canon de superficie establecido en la Ley de Fomento de la Minería". Pero este mandato no fue cumplido ni en el plazo, ni en su contenido.
} 
propuesta de la Dirección General de Minas, previo informe del Instituto Geológico y Minero de España y del Consejo Superior de dicho Departamento, debiendo observarse lo establecido en los artículos 24 al 36 ejusdem. En tanto que los recursos que integran las secciones C y D, serán aprovechados mediante Permisos de Investigación, Permisos de Explotación y Concesiones de Explotación, de acuerdo a lo establecido en los artículos 37 al 81 de la ley en comento.

\section{El debate doctrinario del dominio público en Chile. Teorías chilenas sobre la naturaleza del dominio público minero}

Algunos de los elementos centrales de las discusiones anteriormente expuestas sobre la naturaleza jurídica del dominio público en Francia y España, tuvieron lugar también en Chile. Aunque ahí el debate se planteó con algunas diferencias (para algún autor, más bien deficiencias o deformaciones) ${ }^{69}$. Así que solo una explicación de la evolución de la categoría desde sus bases en el derecho comparado permitiría entender lo que es el dominio público y dentro de él, el género dominio público minero y cómo este fue vagamente y difusamente recogido en la concepción chilena.

A este respecto, debe tenerse en cuenta que el artículo $19 \mathrm{~N}^{\circ} 24$ de la vigente Constitución Política de Chile ${ }^{70}$ (CPCh en adelante), señala que "el Estado tiene el dominio absoluto, exclusivo, inalienable e imprescriptible de todas las minas". Si bien, estas pueden ser concedidas (incluso con las características propias del sistema concesional chileno, que más adelante se detallan), en virtud de esta frase y conforme a lo visto hasta ahora, se constata el sometimiento de las minas a la categoría dominio público. Dicho dominio a primera vista pareciera estar tácitamente influenciado por las teorías patrimonialistas ${ }^{71}$.

Sin embargo, en Chile la literatura históricamente vinculó a las minas y el derecho de minería con una naturaleza jurídica privada. Por eso las teorías que intentan explicar la naturaleza del vínculo de Estado con las minas (además de estar rodeadas de una enorme confusión), suelen ser las tradicionales señaladas al inicio (las cuales resultan para tal fin) o una mezcla de ellas con la categoría dominio público, según se explicará en esta sección.

Por eso, a pesar del tenor de la norma constitucional citada, todavía es posible observar en la literatura jurídico-minera chilena las más diversas opiniones sobre la naturaleza jurídica del dominio público minero. Y, en el ámbito del derecho administrativo no se les tendría en cuenta. Así que no es extraño encontrar en la escasa bibliografía sobre el tema, que algunos autores lo entienden como una expresión del derecho de propiedad ${ }^{72}$; otros, como una forma de potestades públicas ${ }^{73}$; habiendo también quienes entienden que su naturaleza es virtual o eminente ${ }^{74}$. Además,

\footnotetext{
69 VERGARA (1992), p. 234.

${ }^{70}$ Decreto Supremo $\mathrm{N}^{\circ} 100$, de 2005.

${ }^{71}$ Aquí el término patrimonialista es usado en la forma descrita por la doctrina francesa y española, esto es, como una propiedad administrativa, especial o exorbitante del Estado.

${ }^{72}$ Dentro de esta corriente, RODRÍGUEZ (1992), p. 57. Asimismo, aunque no la comparte MORILLO-VELARDE (1992), pp. 19 y 20, explica que esas posiciones han estado influenciadas por lo que en la doctrina española se habría calificado como una forma de propie dad especial o "propiedad modulada", como característica del dominio público. Ver también VERGARA (1990), p. 142, quien se aparta de esta teoría a la que la denomina concepción "patrimonialista", siguiendo la terminología del debate doctrinario planteado en Francia y España. ${ }^{73}$ ENOS (2005), p. 121, considera que resulta "más convincente" entender al dominio público dentro de las potestades públicas. MORILLOVELARDE (1992), p. 97, considera que el dominio público es una titularidad que ampara una pluralidad de potestades públicas de diverso alcance y funcionalidad, siendo la afectación el supuesto o título de tales potestades públicas. Denominada concepción "funcionalista", vinculada a las funciones o potestades del Estado, "muy cercana" a la opinión de VERGARA (1990), pp. 142 y ss.

${ }^{74}$ Como una construcción chilena, derivada de una interpretación de las teorías de PARDESSUS Y PROUDHON, (o de una deformación del nombre de la institución creada ya por GROCIO en 1625, la facultas eminens originaria que realmente era concebido como un derecho de soberanía y no un derecho de propiedad) que además se ser confusa y contradictoria, dista en todo caso de varios aspectos de su
} 
están otros para los que su naturaleza es "mixta"75, e incluso "sui generis"76. Pero en realidad (y esto es muy importante destacarlo), no es sino a partir de la obra de Vergara Blanco ${ }^{77}$, que efectivamente se vincula jurídicamente las minas al Estado a través de la categoría dominio público. La pregunta es ¿por qué? Para dar respuesta a ello conviene explicar en qué consisten las distintas posturas señaladas.

\section{a) El dominio eminente chileno}

Dentro de todo este proceso es importante como punto de partida destacar en qué consistió el dominio eminente en Chile. En ese sentido, para quienes sostuvieron que el dominio del Estado es "radical o eminente", este sería "virtual". En la literatura chilena la virtualidad significó que el Estado solo tendría la facultad de dispensar la constitución de una verdadera propiedad minera a favor de los particulares ${ }^{78}$. Bajo este esquema, el particular se haría dueño del yacimiento descubierto (no solo de los recursos extraídos), dejando al Estado al margen de cualquier tipo de intervención. Este es el rasgo más característico de lo que se llamó la "versión chilena del dominio eminente".

Aunque a primera vista, la utilización del término "dominio eminente" hace recordar a las teorías de Proudhon y sus seguidores, esta versión chilena del mismo corresponde a una interpretación distinta al planteamiento en su fuente original. Fundamentalmente, porque difiere de la concepción de la doctrina francesa (trasladada luego al derecho español según se vio), entre otras cosas, en que, en la Francia de aquel entonces, se negaba cualquier forma de derecho de propiedad sobre los bienes demaniales. El dominio público era un poder de regir y administrar las cosas que por mandato de ley estaban destinadas al uso de todos y cuya propiedad a nadie pertenece.

Es decir, que el dominio eminente en su origen francés no suponía propiedad pública ni privada (también porque en sus inicios no existía tal distinción que hoy en día se tiene), por considerarse que la explicación de su naturaleza no residía en la institución de la propiedad. Pero sería contrario a la esencia del dominio público que la entrega que hiciera el Estado a los particulares de bienes demaniales para su aprovechamiento implicase que este quedara al margen de cualquier tipo de intervención, sobre todo si se tiene en cuenta la mencionada regla de la inalienabilidad de los bienes demaniales. En el contexto francés, el sometimiento de un bien al dominio público no implica propiedad, pero sí podrían implicar la aplicación de normas y principios de derecho público, que ponen sobre el Estado la obligación de protección.

concepción original y que nace de la opinión de CLARO SOLAR, para quien el dominio eminente significaba que en principio, la relación del Estado con las minas radicaba en forma transitoria un dominio especial y sui generis para que luego el particular con el solo hecho de descubrirlas adquiriese el derecho de propiedad sobre ellas. CLARO (1979), pp. 262 y 537 y siguientes. Como expresan ALESSANDRI Y SOMARRIVA (1974), pp. 104 y 105, el principio del dominio eminente era seguido en Chile hasta la reforma constitucional de 1971. VERGARA (1992), p. 234, explica que esta opinión fue seguida casi unánimemente por los autores chilenos civilistas y de derecho minero, de forma acrítica y si más explicación que sus propias afirmaciones. En ese sentido, cita la opinión de RUIZ BOURGEOIS, uno de los autores que más prestigio en el derecho minero chileno, quien pensaba, en 1949, que, a pesar del claro tenor literal del art. 591 del CC (y que reproduciría el art. 1 del Código de Minería de la época), según él, en virtud de seguirse en Chile el llamado "sistema de libertad de minas", el Estado tiene sobre las minas "una propiedad eminente" virtual que solo lo faculta para otorgar los más amplios derechos a aquellos que han cumplido con requisitos legales especiales.

75 PRECHT (1983), p. 742.

${ }^{76}$ VILDÓSOLA (1999), p. 347; OSSA (2012), p. 72; LIRA (2012), p. 40, lo cataloga como dominio público especial.

77 Véase por ejemplo el trabajo de VERGARA (1992), p. 208 que marca el inicio de tal incorporación teórica de las minas al dominio público desde una perspectiva teórica en Chile. Sin embargo, el autor cuenta con una sólida labor investigativa en la que desarrolla su tesis funcionalista.

${ }^{78} \operatorname{ENOS}(2005)$, p. 123. 
En ese contexto comparado, los bienes de dominio público son bienes nacionales que, al formar parte del dominio eminente, se derivarían de un derecho de soberanía y comprenderían todas las cosas que no son propiedad de los individuos ni las corporaciones. Como consecuencia de lo anterior, la Administración se reserva el dictar reglas acerca de su aprovechamiento - que no propiedad- para que ningún interés individual perjudique al uso público al que la ley los destina ${ }^{79}$. Una de las fallas u objeciones que se atribuyó a la teoría del dominio eminente francés, es que no es exacto que el dominio público no pertenece a nadie, porque las cosas tienen que gozar de un titular. Además, que no todos los bienes del dominio público son de uso de todos, si bien, basta con que puedan perseguir un fin público, es decir, que tengan un destino público ${ }^{80}$.

En el derecho chileno, no obstante, algunos autores defienden a la teoría del dominio eminente como parte importante de la tradición minera chilena que se mantuvo de forma predominante en su literatura jurídica, para algún autor no es más que un "mito jurídico" derivado del auto convencimiento de la certeza de sus postulados sin críticas ni objeciones ${ }^{81}$, y desde la reforma constitucional de 1971, fue perdiendo cada vez más fuerza. Aunque todavía es posible encontrar en el derecho minero algunos vestigios de ella ${ }^{82}$.

Lo que resulta curioso es que, en el derecho chileno, con la formulación de la teoría del dominio eminente se ha pretendido explicar o justificar una eventual entrega de las minas a los particulares en "plena propiedad privada" por supuestamente acogerse al sistema de libertad de minas. Pero esto no sería posible conforme a los postulados de su creación francesa original. Como se vio, no era esta la esencia del dominio eminente francés, cuyo contenido habría sido deformado (o flexibilizado) en Chile.

Así pues, esta teoría sí que entró en una verdadera crisis en Chile, lo que cobra fuerza porque en opinión de otro sector a partir de la Constitución Política de 1980, resulta incuestionable que se confirmó la existencia de un dominio patrimonial del Estado sobre las minas. Pero aquí el término "patrimonial" no debe ser entendido como que las minas son bienes privados del Estado sino como equivalente a las teorías "patrimonialistas", es decir, como bienes del dominio público y, por tanto, que constituyen una propiedad especial o exorbitante del Estado, una forma de propiedad eso sí. La eventual consagración de esta perspectiva en el texto constitucional no supondría pues entender que las minas son bienes patrimoniales de este, sino reafirmar que ellas han sido afectadas y, en consecuencia, sometidas a un régimen jurídico especial con las implicaciones del caso.

La principal diferencia entre los dominios eminente y patrimonial chilenos radica en mientras en el dominio patrimonial, el Estado será siempre el dueño de los yacimientos y sus reservas, en tanto no hayan sido extraídos los minerales (los cuales en ese caso pasan a ser propiedad de los particulares); en el eminente, el descubridor se convertiría en dueño del yacimiento y de los minerales aun si estos no han sido extraídos mediante las concesiones plenas.

\footnotetext{
${ }^{79}$ ÁLVAREZ-GENDÍN (1956), p. 26.

${ }^{80}$ ÁLVAREZ-GENDÍN (1956), p. 24.

${ }^{81}$ VERGARA (2001), pp. 213-216. El problema es que en Chile muchas de las opiniones que es posible encontrar en la bibliografía existente carecen de fundamentación y llevan a las más diversas conclusiones, pero al mismo tiempo su reiteración y convencimiento caló profundamente en el quehacer jurídico nacional. Precisamente, ese convencimiento, obligó a dedicar buena parte de la investigación a la indagación de la procedencia de tal mito jurídico, tratando de encontrar algún sustento a sus dichos. Si bien, ya en el artículo AZUAJE (2016), en el que se presentaban avances de este trabajo, se exponía que en opinión de quien escribe la forma más sencilla y adecuada de explicar el dominio público y el sistema concesional minero chileno debe centrarse en términos de potestades del Estado para regular una actividad económica o industrial y no en términos de apropiación o propiedad; consideramos necesario aportar algunos elem entos históricos que den soporte a una u otra teoría en un intento por coadyuvar a dotarlas del sustento jurídico del que carecen.

82 ENOS (2005), p. 123, explica que, con la reforma constitucional de 1971, ya no se puede discutir la existencia de un dominio patrimonial del Estado sobre las minas y que, en la actualidad, a partir de la Constitución de 1980, no solo se confirmó este dominio patrimonial, sino que la idea de dominio radical o eminente se batió en retirada oficial.
} 


\section{b) Dominio mixto y sui generis}

Algunos autores atribuyen al dominio minero una naturaleza "mixta" 83 o "sui generis" 84 "creación original de su constituyente". Dentro de este grupo se considera que no es posible afirmar que el artículo $19 \mathrm{~N}^{\circ} 24$ de la CPCh (y el sistema desarrollado en torno a ella), se adhiere de forma exclusiva y siempre a una sola doctrina, ya que si bien al principio se habla de "todas las minas" a decir de estos autores, para las sustancias no concesibles está previsto el dominio patrimonialista, que no resultaría aplicable a las sustancias concesibles, ya que para estas, la teoría del dominio eminente sería la aplicable. Aunque en este caso el titular se hace dueño de las sustancias no en el momento mismo de la concesión sino, que se hace dueño de un derecho real a extraer los recursos para apropiarlos a medida que los explota ${ }^{85}$.

\section{c) La teoría funcionalista de Vergara Blanco}

Al margen de las posiciones anteriores, destaca y ha sido fundamental para el desarrollo de esta investigación, la opinión del profesor Alejandro Vergara Blanco, quien a través de sus sólidos estudios histórico-jurídicos del derecho administrativo y minero, y en el marco de fuertes críticas a las teorías de los autores chilenos, luego de realizar una reconstrucción de la categoría dominio público, concluyó que no existe la propiedad del Estado sobre los recursos mineros, que esta resulta irreal y que en cuanto a ellos ha operado un acto regulatorio, denominado la publicatio ${ }^{86}$, a partir del cual formula la teoría funcionalista.

La publicatio proviene del derecho romano, e implica en su esencia que ciertos bienes son extraídos de la libre apropiación de los particulares mediante un acto de autoridad, que, en este caso, serían la Constitución y la Ley. Así, este autor al explicar el problema de la naturaleza jurídica de la riqueza mineral señala que si esta ha sido sustraída jurídicamente $a b$ initio tanto de la esfera estatal como de la esfera privada; ha sido "publificada". De ahí que la explicación jurídica de lo que sea la riqueza mineral, provenga del manejo de conceptos de índole pública, no privada. Vergara Blanco entonces, manifiesta su clara conformidad con la existencia de un dominio público minero cuyo carácter es "funcionalista" y no "patrimonialista" 87.

En palabras del autor jurídicamente no existe ni la "propiedad estatal" ni la "propiedad privada" sobre las minas; y las instituciones aplicables son: la publicatio (respecto de la acción regulativa) y los derechos mineros (respecto de las titularidades privadas). Adicionalmente, según él no es sobre las minas que el Estado tiene potestad de regulación, sino más bien, sobre la actividad que es posible desarrollar en torno a tales bienes; esto es, la actividad minera.

Por ello, opina que lo que se busca en la regulación de la Constitución chilena, interpretada en su contexto, al declarar a las minas como de su "dominio", es que la riqueza minera cumpla con la finalidad pública que justifica su publificación, y que el Estado/regulador (legislador) la excluya de la apropiación privada directa por los medios regulares del derecho civil (es decir, ocupación más

\footnotetext{
${ }^{83}$ EVANS DE LA CUADRA (1999), p. 392; PRECHT (1983), p. 742.

${ }^{84}$ VILDÓSOLA (1999), p. 347; OSSA (2012), p. 72; LIRA (2012), p. 40, lo cataloga como dominio público especial.

${ }^{85}$ OSSA (2012), p. 73.

${ }^{86}$ Entre otros trabajos ver: VERGARA (2001), p. 216; VERGARA (2006), p. 231. Para él las opiniones de los autores chilenos, carecen de sustento, de valor en la praxis y en ocasiones son contradictorias o ambiguas. En ese sentido opina que dichas teorías, han pretendido encontrar la explicación de las normas relativas al dominio minero en principios civiles, de derecho privado; los cuales en su opinión son claramente inadecuados para tal fin.

${ }^{87}$ VERGARA (1992), p. 201.
} 
un plazo, lo que posibilita la prescripción adquisitiva); tales finalidades se logran precisamente a través del otorgamiento de derechos a favor de los particulares, por la vía de concesión ${ }^{88}$.

\subsection{El dominio público minero en la regulación vigente en Chile}

Expuesto el escenario que antecede, corresponde preguntarse en primer lugar, si puede o pudo predicarse la existencia de un dominio eminente en Chile y si realmente en la actualidad el texto constitucional establece un dominio público patrimonialista de las minas. Pues, conforme a lo visto, a pesar de su mayor o menor arraigo en la literatura, la teoría del dominio eminente ha sido descartada por autores tales como Vergara Blanco para quien, en su interpretación chilena, careció y carece actualmente de sustento, y la Constitución Política vigente no la recoge ${ }^{89}$, con lo cual resultaría anacrónico e inadecuado invocarla ${ }^{90}$.

Pues bien, de la lectura de los artículos19 N²4 $\mathrm{CPCh}^{91}$, y 591 del Código Civil (CC) ${ }^{92}$ (sin que pueda perderse de vista, el contenido de la Ley Orgánica Constitucional de Concesiones Mineras y del Código de Minería) resulta que "el Estado es dueño de todas las minas (...)" lo que lleva claramente a sostener una primera conclusión: la existencia de un dominio público, así que puede efectivamente hablarse de un dominio público minero ${ }^{93}$.

Corresponde entonces ofrecer una opinión propia sobre si este es un dominio eminente o "dominio-potestad", publicatio o título de intervención del Estado, un dominio patrimonialista, o bien, si es que ciertamente su carácter es mixto o sui generis. En ese sentido, el artículo 19 constitucional en su $\mathrm{N}^{\circ} 24$, establece por una parte un "derecho a la propiedad" según el cual es posible adquirir libremente el dominio de toda clase de cosas, así como el "derecho de propiedad" de acuerdo con el que, una vez adquirida esta sobre dichos bienes, se tendrá toda la protección necesaria. Siendo esta misma norma la que más adelante establece el régimen del dominio sobre los recursos minerales en el país. En ese mismo sentido, no obstante su proclamación constitucional, es cierto que la propiedad no es absoluta, de modo que pueden existir algunas limitaciones de las cuales derivan regímenes distintos ${ }^{94}$.

En efecto, existen bienes en los cuales la propiedad no podría ser eliminada por completo, y otros en los cuales resulta imposible extenderla ${ }^{95}$. Correspondiendo a los operadores políticos, económicos y jurídicos en el marco de sus competencias, tomar las decisiones en cuanto a si ciertas cosas estarán dentro o fuera del mercado, y el límite de tales consideraciones, así como la determinación de aquellas cosas que permanecerán en poder del Estado y de aquellas que quedarán entregadas al dominio privado ${ }^{96}$.

Es a través de instrumentos orientados por políticas públicas, que se emprenden determinadas acciones con objetivos que hacen surgir las normas jurídicas contentivas de las decisiones tales como, aquellas que recaen sobre la titularidad de los bienes. Lo que ha dado lugar a que la doctrina considere la existencia de "diversas propiedades" o "propiedades especiales," con estructuras particulares que relativizan el tradicional modelo de la propiedad monista de los códigos

${ }^{88}$ VERGARA (2006), p. 224.

89 VERGARA (2001), p. 216; VERGARA (2006), p. 231.

90 VERGARA (2006), p. 217.

${ }^{91}$ Decreto Supremo $\mathrm{N}^{\circ} 100$, de 2005.

${ }^{92}$ Decreto con fuerza de Ley Número 1, de 2000.

${ }_{93}$ Para RUZ (2011), p. 38, las minas se encuentran dentro de la noción de dominio público terrestre, aquel que comprende todos los bienes nacionales que se encuentran en la superficie terrestre.

${ }^{94}$ VERGARA (2010), p. 351.

${ }^{95}$ MIGUEZ (2014), p. 7.

${ }_{96}$ PENAILILLO (2007), pp. 81-82. 
civiles $^{97}$.

Ahora bien, de acuerdo con los artículos 589 y siguientes del CC, en Chile los bienes o son públicos (esto es, apropiables por su naturaleza, no comerciables por su destino, salvo excepción) o son privados (esto es, apropiables y comerciables) ${ }^{98}$. Y a este respecto, haciendo una interpretación de las normas contenidas en la CPCh y el $\mathrm{CC}^{99}$, la excepción a la garantía de que todos los bienes son libremente apropiables, viene dada por tres categorías a saber: a) los bienes comunes a todos los hombres; b) los bienes públicos, como las calles y las aguas; $y, c)$ los señalados en la propia CPCh como no libremente apropiables.

Considerando todo lo visto, en esta última categoría se encuentran las minas, las que a pesar de no compartir las características de los bienes comunes a todos los hombres o de las calles y las aguas, no son libremente apropiables, porque han sido claramente afectadas al dominio público según lo dispuesto en el artículo $19 \mathrm{~N}^{\circ} 24$ inciso $6^{\circ}$ de la CPCh y el artículo 591 del CC.

De forma similar a lo que ocurría en la publicatio romana, en la que ciertos bienes adquirían el carácter demanial por un acto de autoridad, la propia Constitución Política reviste a las minas con el ropaje del dominio público, el cual recubre las más variadas cosas ${ }^{100}$, lo que más que una mera declaración no es otra cosa que su afectación. Es decir, su sometimiento a un régimen especial y exorbitante de derecho público, no privado. La afectación que como se ha visto, constituye la esencia misma del dominio público, sustraer ciertos bienes de la libre apropiación por motivos de interés público. De tal suerte que efectivamente, ha ocurrido esa publificación de la que hablaba Vergara Blanco ${ }^{101}$.

Lo que ocurre es que el mencionado artículo $19 \mathrm{~N}^{\circ} 24$ constitucional, desde su inciso primero hasta el quinto reconoce el derecho de propiedad, de la misma forma que el $\mathrm{N}^{\circ} 23$, establece la libertad para adquirir toda clase de bienes, mientras el inciso sexto del artículo $19 \mathrm{~N}^{\circ} 24$, en sentido contrario a la regla general de apropiabilidad privada de los bienes, declara como se ha mencionado que "el Estado tiene el dominio absoluto, exclusivo, inalienable e imprescriptible de las minas". Estableciéndose seguidamente, la posibilidad de que los particulares obtengan concesiones mineras "protegidas por el derecho de propiedad".

Es la confusa técnica empleada en la redacción de la norma lo que da lugar a contradictorias interpretaciones sobre el dominio minero en Chile, al ser considerado un cuadro difícil de armonizar aisladamente $^{102}$. De cualquier forma, una interpretación estrictamente gramatical, no resulta suficiente. Así pues, el panorama se aclarará si se tiene en cuenta que el propio texto constitucional dispone ciertos límites y que corresponde a la ley determinar qué sustancias de aquellas a las que se refiere el inciso sexto del artículo $19 \mathrm{~N}^{\circ} 24$, exceptuados los hidrocarburos líquidos o gaseosos, pueden ser objeto de concesiones de exploración o explotación.

\subsubsection{Las concesiones mineras según la CPCh y sus normas de desarrollo}

La CPCh señala como características de las concesiones de exploración o explotación: que se constituirán por resolución judicial (no administrativa como ocurre en otros ordenamientos), tendrán la duración, conferirán los derechos, e impondrán las obligaciones que la ley exprese. Ley

\footnotetext{
${ }^{97}$ Sobre este aspecto véase a CORDERO (2008), pp. 513-515; también la obra de ALBALADEJO Y RODRÍGUEZ (1992).

98 VERGARA (2010), p. 352; MIGUEZ (2014), p. 10.

${ }^{99}$ Artículos 585 y siguientes.

100 PAREJO ALFONSO (1983), p. 2390.

101 VERGARA (2006), p. 224.

102 También catalogado de "injerto constitucional" FERMANDOIS (2010), pp. 407-419.
} 
que, por cierto, debe tener el carácter de orgánica constitucional, y hoy en día no es otra que la: Ley Orgánica Constitucional de Concesiones Mineras (LOCCM), que viene a completar el cuadro del sistema chileno con el Código de Minería $(\mathrm{CM})^{103}$.

El marco constitucional, expresa además que la concesión minera obliga al dueño a desarrollar la actividad necesaria para satisfacer el interés público que justifica su otorgamiento, que el régimen de amparo será establecido en dicha ley, la cual tenderá directa o indirectamente a obtener el cumplimiento de esta obligación. Así que se contemplan causales de caducidad para el caso de incumplimiento o de simple extinción del dominio sobre la concesión. Asimismo, se distingue entre sustancias concesibles y sustancias no concesibles, lo cual da la primera idea de que estas, no están sujetas al mismo régimen por tratarse de supuestos de hecho y de derecho diferentes.

La concesibilidad o no concesibilidad de ciertas sustancias minerales viene dada en virtud de la Constitución y la Ley ${ }^{104}$. En efecto, tal y como lo dispone el artículo 5 del CM, son concesibles, o denunciables, las sustancias minerales metálicas y no metálicas y, en general, toda sustancia fósil, en cualquier forma en que naturalmente se presente, incluyéndose las existentes en el subsuelo de las aguas marítimas sometidas a la jurisdicción nacional, a las que se tenga acceso por túneles desde tierra ${ }^{105}$.

En tanto que, son sustancias no concesibles, como su nombre lo indica, aquellas que no son susceptibles de concesión minera judicial, esto es, los hidrocarburos líquidos o gaseosos, el litio, los yacimientos de cualquier especie existentes en las aguas marítimas sometidas a la jurisdicción nacional, los yacimientos de cualquier especie situados, en todo o en parte, en zonas que, conforme a la ley, se determinen como de importancia para la seguridad nacional con efectos mineros ${ }^{106}$.

De la distinción entre ambas categorías surge una consecuencia inmediata y es que su tratamiento constitucional y legislativo es distinto. Tal y como explica Enos ${ }^{107}$, las sustancias concesibles podrán ser objeto de concesiones de exploración o explotación, lo que significa que son susceptibles del derecho de aprovechamiento, originado en un procedimiento concesional, cuyo título es la concesión otorgada por el órgano que en este caso, tiene carácter jurisdiccional, y que confiere al titular los derechos de exclusividad y preferencia a explorar y explotar las sustancias minerales, que le permitirán, en definitiva, apropiarse de ellas. La concesión minera en todo caso debe ser amparada mediante el pago de lo que se ha llamado la patente anual.

\footnotetext{
${ }^{103}$ Ley N 18.097, de 1982 y Ley № 18.248, de 1983, respectivamente. El Código de Minería en su artículo 1, en la misma línea bajo estudio establece que: "El Estado tiene el dominio absoluto, exclusivo, inalienable e imprescriptible de todas las minas, comprendién dose en éstas las covaderas, las arenas metalíferas, los salares, los depósitos de carbón e hidrocarburos y las demás sustancias fósiles, con excepción de las arcillas superficiales, no obstante la propiedad de las personas naturales o jurídicas sobre los terrenos en cuyas entrañas estuvieren situadas.

Pero toda persona tiene la facultad de catar y cavar para buscar sustancias minerales, con arreglo al párrafo $2^{\circ}$ de este título, y también el derecho de constituir concesión minera de exploración o de explotación sobre las sustancias que la ley orgánica constitucional declara concesibles, con la sola excepción de las personas señaladas en el artículo 22".

104 Recuérdese que como se indicó la Constitución exceptúa a los hidrocarburos líquidos y gaseosos, pero deja a la LOCCM la determinación de las demás sustancias concesibles. Aunque no es tema central de esta investigación, debe advertirse que algunos constitucionalistas se han manifestado a favor de un recurso de inaplicabilidad por inconstitucionalidad sobre la LOCCM, no obstante, que el Tribunal Constitucional ha revisado su constitucionalidad (Sentencia del 6/9/83, Rol 18), y cuando ha sido resuelto que un determinado precepto legal es constitucional, la Corte Suprema no podrá declararlo inaplicable por el mismo vicio (art. 83 inc. final de la Constitución), por lo que la Corte Suprema tendría limitada su jurisdicción y no podría revisar las normas que determinaron la concesibilidad de las sustancias mineras, por la vía de la inaplicabilidad. ENOS (2005), p. 125.

105 También Artículo 3 inciso 2은.

${ }^{106}$ Artículo 19 № 24 inciso 70 de la CPCH; Artículo 3 inciso 40 LOCCM y Artículo 7 CM.

107 ENOS (2005), p. 125.
} 
Esa patente anual está prevista en los artículos 142 y siguientes CM y el artículo 12 LOCCM $^{108}$, que establecen el régimen de amparo como una condición para mantener los derechos derivados de la concesión. Para Vergara Blanco ${ }^{109}$ esta exigencia se constituye como un amparo indirecto del derecho respectivo, lo cual se encontraría dentro del marco de la constitución, que deja la puerta abierta para que dicho régimen fuese directo o indirecto.

De acuerdo con el autor, es una decisión de política económica coherente con el sistema instaurado en la CPCh, que es de amplia libertad para el particular en el espacio de sus derechos; lo que a su decir, es reconocidamente un sistema liberal ${ }^{110}$, que tiene por virtud impedir que sea el Estado el que tome las decisiones económicas sobre la oportunidad en la que de acuerdo a una regulación dada, se debe aprovechar la riqueza mineral, dejando a los particulares la decisión al respecto, consagrando para ello la libertad de acceso (Art. 19 N23 CPCh), dando mucha protección y certeza a los títulos privados (Art. 19 N 24 CPCh).

Pero, nótese aún más dos elementos importantes que no pueden perderse de vista: por una parte como se dijo, las concesiones mineras en Chile, se constituirán por resolución de los tribunales ordinarios de justicia, en procedimiento seguido ante ellos y sin intervención decisoria alguna de la Administración o de otra autoridad o persona y; por otra parte, si el Estado estimare necesario ejercer las facultades de explorar con exclusividad y explotar sustancias concesibles, deberá actuar por medio de empresas de las que sea dueño o en las cuales tenga participación, que constituyan o adquieran la respectiva concesión minera y que se encuentren autorizadas para tal efecto de acuerdo con las normas constitucionales vigentes (Artículo 5 LOCCM).

De ahí que cabe preguntarse: ¿tiene algún sentido que el Estado deba someterse a un procedimiento concesional sobre bienes que son suyos en "propiedad" ya sea esta privada o especial? Lo cierto es que no, no lo tiene. Entonces, ¿Es inconstitucional la LOCCM?

Es discutible, en efecto para quienes sostienen las concepciones patrimonialistas la LOCCM vació de contenido el dominio patrimonialista chileno plasmado en la Constitución de 1980, porque el artículo 5 LOCCM, no hace otra cosa que proclamar la concepción denominada "dominio subsidiario del Estado", esto es, el dominio eminente en la versión chilena. Lo cual resulta de dudosa constitucionalidad, dejando el camino abierto el camino para futuros reclamos. De cualquier forma, según el artículo $11 \mathrm{n}^{\circ} 2$ de la LOCCM el concesionario de la explotación solo tiene el derecho exclusivo de todas las sustancias minerales que extraiga, lo cual significa implícitamente que el

\footnotetext{
108 LOCCM: "Artículo 12.- El régimen de amparo a que alude el inciso séptimo del número $24^{\circ}$ del artículo 19 de la Constitución Política consistirá en el pago anual y anticipado de una patente a beneficio fiscal, en la forma y por el monto que determine el Código de Minería. Las deudas provenientes de patentes no pagadas sólo podrán hacerse efectivas en la concesión respectiva, sin perjuicio de su caducidad conforme a la letra a) del inciso primero del artículo 18. Lo pagado por patente minera por una concesión de explotación se imputará al pago del impuesto a la renta que derive de la actividad minera realizada en la respectiva concesión, con arreglo a lo que determine el Código de Minería".

${ }^{109}$ VERGARA (2010), p. 397.

${ }^{110}$ Aunque, FERMANDOIS (2011), pp. 39-40, opina que: "(...) La verdad es que nuestra Ley Fundamental no constitucionaliza ni un modelo económico ni políticas determinadas. Además y dependiendo de lo que se entiende por tal, puede afirmarse que tampoco eleva a rango constitucional un "sistema económico" determinado. Salvo señalados preceptos específicos en materia de disciplina fiscal o política monetaria, lo que hizo la Carta fue ingresar a materias económicas fundamentales para completar el cuadro valórico básico por el que primeramente opta, fundado en la libertad del hombre y en su primacía sobre el Estado. En otras palabras, la identificación y formulación de los pilares económicos fundamentales en la propia Constitución es una consecuencia forzosa derivada de los principios inspiradores reconocidos por el propio constituyente del Capítulo I de las Bases de la Institucionalidad. La omisión de toda garantía, principio de actividad para la relación Hombre-Estado u opción en materia económica, habría significado una severa laguna constitucional, una zona de agnosticismo institucional inaceptable para una concepción integral de la sociedad que se pretende fundar, en la que se postula que los principios y valores esenciales que la fundan, la informan en su totalidad, sin exclusiones. Creemos que, en estricto rigor, el Código Fundamental que nos rige permite la implementación de modelos y políticas económicas muy diversas, desde las más socializantes hasta otras acentuadamente liberales, en cuanto no excedan el marco amplio de libertad que lo funda". (cursivas, subrayado y negrillas propias).
} 
concesionario no es dueño de las reservas sino de lo extraído. Y hasta el momento, aunque en alguna oportunidad se suscitaron dudas sobre la constitucionalidad de la Ley, una eventual inconstitucionalidad ha sido descartada por el Tribunal Constitucional ${ }^{111}$.

\section{Reflexiones finales: ¿cómo puede explicarse dogmáticamente el dominio público minero en Chile?}

En primer lugar, para quien escribe, las particularidades del sistema minero chileno dejan en evidencia que las minas forman parte de la categoría doctrinaria dominio público, aunque su evolución y discusiones hayan tomado algunas variaciones con respecto al origen francés y español que se expuso al inicio. En ese sentido, pese a la falta de técnica jurídica que se atribuye a la redacción del artículo 19 número 24 de la CPCh; a pesar de las disposiciones dudosas, de los errores, confusiones y falta de motivación doctrinaria de la teoría del dominio eminente en su versión chilena (que han llevado a algunos autores a desecharla por considerarla carente de sustento); $y$, por anacrónico que pudiera resultar; la forma más adecuada de explicar la naturaleza del dominio público minero declarado en el texto constitucional y que se ha erigido conforme a las demás leyes que lo complementan, más que un tema de propiedad o de soberanía, es un tema de ordenación de esta categoría de bienes. No se trata pues de un dominio patrimonialista, ni de bienes patrimoniales del Estado.

Se trata entonces de una evolución de lo que fue la doctrina francesa original del dominio eminente. Que, en efecto, no implica ni implicó nunca propiedad pública ni privada sino un régimen jurídico distinto. Rescatar aquella idea del dominio eminente en su fuente francesa, pierde su anacronismo y solo puede entenderse en el contexto actual, si se aplican conceptos como las potestades, funciones y competencias del Estado constitucional moderno.

Si se entiende que se está frente a un conjunto de potestades públicas, que someten a ciertos bienes, derechos o actividades a un tratamiento especial de derecho público, donde los grados de intervención del Estado, serán mayores o menores dependiendo de las circunstancias históricas, políticas y jurídicas, que se concretarán en forma de leyes y demás disposiciones. Así que conviene desterrar cualquier incidencia de visiones de derecho privado de lo que deba entenderse por dominio público minero.

A la Constitución chilena puede hacerse extensible lo que se expresó en el derecho comparado español en palabras de Villar Palasí, Parejo Gamir y Rodríguez Oliver, Gallego Anabitarte, Parejo Alfonso ${ }^{112}$, esto es, que establece un sistema de ordenación de competencias; un haz de potestades sobre una actividad históricamente importante para el país, reservándose el ejercicio directo de la actividad respecto de unas sustancias y sometiendo otras a un sistema concesional para su aprovechamiento.

\footnotetext{
${ }^{111} \mathrm{Al}$ respecto puede consultarse la sentencia del Tribunal Constitucional TC/5 de 9 de noviembre de 1981. Ella contiene un requerimiento formulado por la Junta de Gobierno a fin de que el TC resolviera una cuestión de constitucionalidad que se suscitó en la tram itación del proyecto de la LOCCM. El punto fue discernir si la determinación de las sustancias concesibles y las no concesibles era o no materia de una Ley Orgánica Constitucional (LOC). Ello en virtud de lo dispuesto en el № 24 del Artículo 19 de la CPCh, que menciona el término "ley" para referirse a las sustancias que pueden ser o no concesibles, pero poco después habla expresamente de LOC cuando se refiere a la duración, derechos y obligaciones asociadas a una concesión. Consúltese también la sentencia TC/10 de 22 de diciembre de 1981 y la TC/18 del 6 de septiembre de 1983. Aunque en otras oportunidades la jurisprudencia ha tenido oportunidad de pronunciarse sobre peticiones de inconstitucionalidad relativas a algunas normas particulares de la LOCCM, debe tenerse en cuenta ante todo, que el debate sobre la naturaleza jurídica del dominio público minero es fundamentalmente doctrinario. Esto explica porqué no abunda la jurisprudencia antigua ni actual sobre la materia.

112 VILLAR (1964) Y VILLAR (1968); PAREJO (1975); PAREJO Y RODRÍGUEZ (1976); GALLEGO (1982), pp. 227-309, y GALLEGO (1983), pp. 13-420; PAREJO (1983), pp. 2379-2422.
} 
Dicha opinión fue incorporada en Chile con ciertos matices por Vergara Blanco a lo largo de su obra, aunque él como se mencionó, prefiere referirse a su tesis funcionalista y para evitar confusiones, descarta absolutamente la existencia de un eventual dominio eminente del Estado, sobre todo por la forma en la que este fue entendido y aplicado por algunos autores chilenos ${ }^{113}$. Pero en opinión de quien escribe, incluso si aquellos yerran en la interpretación y explicación de lo que fue el dominio eminente francés, ello no excluye el hecho de que es este último el sistema que - con variaciones - se ha erigido en el país, como una evolución de la doctrina francesa.

En todo caso, al excluir la idea de una propiedad pública o privada sobre las minas no desaparece el carácter demanial de estas. Decir que el Estado realmente no es el "dueño" de las minas no equivale per se a su desvinculación de ellas. Porque en el dominio público se limita su esfera de actuación a un ámbito de potestades, funciones y competencias, lo cual resulta la forma más adecuada de explicar la institución. Y ello implica que efectivamente, cualquier pretendida participación de este como "propietario" tendría que ser descartada, porque efectivamente no lo es.

Ahora bien, a pesar de las consideraciones anteriores, lo cierto es que sea que se entienda como dominio-potestad o dominio-propiedad, incluso las concepciones patrimonialistas no excluyen la posibilidad de reconocer y aplicar reglas exorbitantes a los bienes de dominio público debido a su afectación a la satisfacción del interés público o el fomento de la riqueza nacional.

Esto quiere decir que, a pesar de los vaivenes en la actualidad la doctrina está consciente de que una de las más importantes consecuencias de someter a ciertos bienes a la categoría de dominio público, es que su régimen jurídico supondrá una o varias excepciones tanto teóricas como prácticas a lo que podría llamarse la propiedad ordinaria o propiedad civil. ¿Cuáles pueden ser esas excepciones? Ello dependerá de los límites que impone el Estado de Derecho y, en definitiva, de cada ordenamiento jurídico. Pero siempre que exista la afectación, elemento esencial de la noción de dominio público en una u otra concepción, habrá de fondo alguna forma de interés público que el Estado tendrá que garantizar. Y es esto lo que ocurre con las minas.

El sometimiento de las minas al dominio público lo que hace es vincularlas a un régimen especial, con mayores o menores grados de intervención o regulación Estatal, dependiendo del ordenamiento jurídico en cuestión. En definitiva, la intención del dominio público es, por una parte evitar la libre apropiación por los particulares, y por otra parte, precisamente no excluir por completo la intervención del Estado, por lo que en Chile no quiere suponer tampoco una renuncia total a su vinculación con las mismas, pues a pesar de las amplias facilidades que otorga el ordenamiento jurídico a los concesionarios mineros, la realidad es que el Estado mantiene con ellas una especie de "cordón umbilical irrompible" que hace que entre otras cosas, las minas y la actividad minera en su conjunto estén rodeadas de una serie de obligaciones especiales. Una de ellas es, la existencia del régimen de amparo a través de la exigencia de la patente anual como una de las condiciones para mantener la concesión.

El sistema concesional vigente en Chile implica entonces la posibilidad de que el Estado ejerza las actividades directamente (sustancias no concesibles). Y, en el caso de sustancias concesibles, mediante concesiones judiciales a través de procedimientos previstos tanto para particulares como para el propio Estado. En base a esta consideración, si bien en el dominio minero chileno, se distingue entre bienes concesibles y no concesibles, con ello no se está consagrando un régimen mixto o distinto del sistema demanial. Solo se hace una mera reserva de ejercicio directo de algunas actividades y se impone la necesaria concesión de otras. Ello en virtud de la noción misma

${ }^{113}$ VERGARA (2001), pp. 213-216. 
de dominio público es perfectamente posible, si se entiende que no es otra cosa que un sistema de ordenación en base a un conjunto de potestades.

En consecuencia, si bien en la doctrina comparada suele prevalecer la perspectiva del dominio público (y por tanto, del dominio minero) como una propiedad especial, en el caso de Chile, si se entiende que la regulación contenida en la Constitución Política consagra un título de intervención o conjunto de potestades (una versión moderna del dominio eminente francés en los términos propuestos por la doctrina francesa y no en los términos propuestos por la doctrina chilena), o bien, la publicatio o tesis funcionalista expuesta por Vergara Blanco; y no la existencia de una propiedad pública o privada de las minas, resulta mucho más sencilla y adecuada (al menos desde el punto de vista teórico) la explicación el sistema concesional minero que se ha erigido en país, como un conjunto de facultades o potestades para la regulación de una actividad económica extremadamente compleja como es la minería. Por lo que sin duda es innegable que en la actualidad puede hablarse de que existe un dominio público minero.

\section{BIBLIOGRAFÍA CITADA}

ALBALADEJO GARCÍA, MANUEL Y RODRÍGUEZ GARCÍA, CARLOS JAVIER (1992): Una nueva sistematización jurídica de las propiedades especiales (Madrid, Dykinson).

ALESSANDRI RODRÍGUEZ, ARTURO Y SOMARRIVA UNDURRAGA, MANUEL (1974): Curso de derecho Civil, los bienes y los derechos reales (Santiago, Editorial Nascimento).

ÁLVAREZ-GENDÍN, SABINO (1956): “El dominio público. Su fundamento y naturaleza jurídica”, en: A.A.V.V., Estudios dedicados al profesor Gascón y Marín en el cincuentenario de su docencia (Madrid, Instituto de Estudios de Administración Local), pp. 259-302.

(1956): El dominio público. Su naturaleza jurídica (Barcelona, BOSCH).

AZUAJE PIRELA, MICHELLE (2016): “Dominio Minero, tributación y regalías mineras en Chile”, en: Revista Anales de Legislación Argentina (Año LXXVI, N 33), pp. 105-126.

BARCELONA LLOP, JAVIER (1995): “Novedades en el régimen jurídico del dominio público en Francia”, en: Revista de Administración Pública 549 (N¹37), pp. 549-576.

Betancourt SERnA, FernANDo (2010): Derecho Romano Clásico, Cuarta Edición (Sevilla, Publicaciones de la Universidad de Sevilla).

BRARD, YVES (1994): Domaines public et privé des personnes publiques (Paris, Éditions Dalloz).

CASINO RUBIO, MIGUEL (2009): "La distribución de competencias entre el Estado y las Comunidades Autónomas para la regulación de la propiedad privada y el régimen de los bienes demaniales y patrimoniales de las Administraciones Públicas en la doctrina del Tribunal Constitucional”, en: Parejo, Luciano y Palomar, Alberto (director), Derecho de los bienes públicos. Parte General (Pamplona, Thomson Reuters, Aranzadi), tomo I, pp. 97-118. 
CATALANO, EDMUndo F. (1.960): Curso de Derecho Minero y Régimen Legal de Petróleo y de los Minerales Nucleares (Buenos Aires, Impresora Oeste).

(1999): Código de Minería Comentado (Buenos Aires, Zavalia).

CAZORLA PRIETO, LUIS MARÍA (1983): Temas de Derecho Administrativo, Tercera Edición (Madrid, Servicio de Publicaciones del Ministerio de Economía y Hacienda).

CHEMÁS, SERGIO (2015): “Dominio Público y los Bienes Públicos: Europa y América Latina ¿El hijo Sigue Mirando al Padre?”, en: Revista Digital de Derecho Administrativo (Vol. 14), pp. 223-236.

CLARO SOLAR, LUIS (1979): Derecho Civil Chileno (Santiago, Editorial Jurídica de Chile), Tomo IV.

COLMEIRO, MANUEL (1850): Derecho administrativo español (Madrid, Imprenta y Librería de Eduardo Martínez. Edición facsímil, 1995, Santiago de Compostela, Escola Galega de Administración Pública), 2 vol.

CORDERO QUINZACARA, EDUARDO (2008): "De la propiedad a las propiedades: La evolución de la concepción liberal de la propiedad", en: Revista de Derecho de la Pontificia Universidad Católica de Valparaíso (N³1), pp. 493-525.

(2019): Dominio público, bienes públicos y bienes nacionales. Bases para la reconstrucción de una teoría de los bienes públicos (Santiago, Tirant Lo Blanch).

CORONEL, GUSTAVO (1983): The nationalization of the Venezuelan oil industry (Massachusetts, Lexington Books).

DARNACULLETA I GARDELLA, MERCÈ (2000): Recursos naturales y dominio público: el nuevo régimen del demanio natural (Barcelona, Cedecs).

DE ARCENEGUI, ISIDRO (2002): Derecho Minero (Madrid, Civitas).

DIEZ-PICAZO Y PONCE DE LEÓN, LUIS (1954): “Naturaleza jurídica de los minerales ¿Tienen o no la condición de frutos?", en: Anuario de Derecho Civil (Vol. 7, № II), pp. 355-376.

DUFAU, JEAN (1977): Le domaine public (Paris, Editions du Moniteur).

DUGUIT, LÉON, (1930): Traité de droit constitutionnel (París, Ancienne Librairie Fontemoing \& Cie.), tomo III.

ENOS AGUIRRE, RAFAEL (2005): Derecho de Áridos (Santiago, Lexis Nexis).

EVANS DE LA CUADRA, ENRIQUe (1999): Los Derechos Constitucionales, Segunda Edición (Santiago, Editorial Jurídica de Chile), Tomo III. 
FERMANDOIS VÖHRINGER, ARTURO (2010): Derecho Constitucional Económico, Segunda Edición (Santiago, Ediciones Universidad Católica de Chile), Tomos I y II.

FERNÁNDEZ DE VELASCO, RECAREDO (1921): “Naturaleza jurídica del dominio público según Hauriou. Aplicación a la legislación española”, en: Revista de Derecho Privado (N 94-95), pp. 230-236.

FRANCH ISAGUER, MARTA (1996): “Imbricación del dominio público y privado", en: Revista de Administración Pública ( $N^{\circ} 139$ ), pp. 419-443.

FRANCISKOVIC INGUNZA, MILLITZA (2016): "Sistemas de dominio originario de los yacimientos", en: Vox Juris (Vol. 30, N²), pp. 143-153.

GAllego ANABItARTE, ALFREdo (1982): "Los cuadros del Museo del Prado (I). Reflexiones histórico y dogmático-jurídicas con ocasión del artículo 132 (y 133.1) de la Constitución española de 1978”, en: Presidencia Del Gobierno (editor), Administración y Constitución. Estudios en homenaje al profesor Mesa Moles (Madrid, Presidencia del Gobierno), pp. 227-309.

(1986): "El derecho español de aguas en la historia y ante el derecho comparado", en: Gallego, Alfredo, Menéndez, Ángel y Díaz, José (editores), El derecho de aguas en España (Madrid, Ministerio de Obras Públicas y Urbanismo, Centro de Publicaciones), pp. 13-420.

GARCÍA DE ENTERRÍA, EDUARDO (1984-1985): Apuntes de Derecho Administrativo, Tercera Edición (Madrid, Civitas).

(1998): Dos estudios sobre la usucapión en derecho administrativo, Tercera Edición (Madrid, Civitas).

GARCÍA DE ENTERRÍA, EDUARDO Y ESCALANTE, JOSÉ ANTONIO (1982): Legislación Administrativa, Cuarta Edición (Madrid, Civitas).

GARRIDO FALLA, FERNANDO (1962): "Sobre el régimen del dominio público", en: A.A.V.V., Problemática de la ciencia del derecho. Estudios en homenaje al profesor José María Pi y Suñer (Barcelona, Bosch), pp. 303-340.

(2002): Tratado de derecho administrativo. II. Parte general: conclusión, Décima Primera Edición (Madrid, Tecnos).

GIUFFRÉ EDITORE (1964): Enciclopedia del Diritto, XII (Varese, Italia).

GONZÁleZ BERTI, LUIS (1969): Compendio de Derecho Minero Venezolano (Mérida, Publicaciones de la Facultad de Derecho de la Universidad de Los Andes), Volumen I.

GONZÁLEZ GARCíA, JULIO (2009): “Notas sobre el régimen general del dominio público”, en: González, Julio (director), Derecho de los bienes públicos, 2ª edición (Valencia, Tirant Lo Blanch Editores), pp. 67-108. 
(1998): La Titularidad de los Bienes del Dominio Público (Madrid, Marcial Pons).

GONZÁLEZ-BERENGUER URRUTIA, JOSÉ LUIS (1968): "Sobre la crisis del concepto de dominio público", en: Revista de Administración Pública (Vol. 18, № 56), pp. 191-220.

GORDILLO, AGUSTín (2014): Tratado de Derecho Administrativo y obras selectas, primeros manuales (Buenos Aires, Agustín Gordillo y Fundación de Derecho Administrativo), Tomo 9.

GUAITA, AURELIO (1956): "Le domaine public en Espagne,", en: Revue Internationale des Sciences Administratives ( $\left.\mathrm{N}^{\circ} 22\right)$, pp. 121-140.

(1986): Derecho Administrativo. Aguas, montes, minas (Madrid, Civitas).

HAURIOU, MAURICE (1897): Précis de droit administratif et de droit public general (París, L.Larose).

HONORIO MARTíNEZ, JOSÉ (2011): "La política petrolera del gobierno de Chávez o la redefinición del Estado ante la globalización neoliberal”, en: Revista Historia Actual ( $\left.N^{\circ} 24\right)$, pp. 7-15.

IGLESIAS, JUAN (1999): Derecho Romano, Décima Segunda Edición (Madrid, Editorial Ariel).

INGRAM, GEORGE (1974): Expropriation of U.S. Property in South America. Nationalization of oil and copper companies in Peru, Bolivia and Chile (Michigan, Praeger Publishers).

LIRA OVAlLE, SAMUEL (2012): Curso de Derecho de Minería, Séptima Edición (Santiago, Editorial Jurídica de Chile).

MAIRA AGUIRRE, LUIS (1970): "El camino a la nacionalización del cobre", en: Revista de Derecho Económico (N²7-28), pp. 29-30.

MANSILLA, HUGO (1980): "La revolución de 1952 en Bolivia: un intento reformista de modernización", en: Revista de Estudios Políticos ( $\left.N^{\circ} 17\right)$, pp. 117-128.

MARTíneZ VÁZQUeZ, FRANCISCO (2000): “¿Qué es el dominio público?”, en: Themis, Revista de Derecho (N40), pp. 263-276.

MARTín-RETORTILLO, CIRILO (1952): "Los frutos de las minas", en: Anuario de Derecho Civil (Tomo V, fascículo III), pp. 1019-1048.

MELLER, PATRICIO (1996): Un siglo de economía política chilena 1890-1990 (Santiago, Editorial Andrés Bello).

MENÉNDEZ REXACH, ÁNGEL (2016): "El dominio público como institución jurídica: configuración histórica y significado actual en el derecho público español”, en: Revista jurídica Universidad Autónoma de Madrid ( $\left.N^{\circ} 10\right)$, pp. 209-223. 
MIGUEZ NÚÑEZ, RODRIGO (2014): "De las cosas Comunes a todos los hombres. Notas para un debate", en: Revista Chilena de Derecho (Vol. 41, N¹), pp. 7-36.

MORILlo-Velarde PÉREZ, José (1992): Dominio Público. Estudios Trivium, Administrativo (Madrid, Editorial Trivium).

NIETO GARCÍA, ALEJANDRO (1987): "La nueva regulación de los bienes comunales", en: Revista de Estudios de la Administración Local y Autonómica (N²33), pp. 9-22.

ORTIZ MONSALVE, ÁLVARO (1992): Derecho de Minas (Bogotá, Editorial Temis).

OSSA BULNES, JUAN LUIS (2012): Tratado de derecho de minería, Quinta Edición (Santiago, Editorial Jurídica de Chile).

PADILLA, FRANCISCO (1950): Curso de Derecho Minero Argentino (Tucumán, Instituto de Derecho Público, Universidad Nacional de Tucumán).

PARDESSUS, JEAN MARIE (1811): Traité des servitudes ou fonciers, les príncipes des nouveaux codes (París, Garnery, Libraire, Rue de Seine).

PAREJO ALFONSO, LUCIANO (1983): "Dominio público: un ensayo de reconstrucción de su teoría general", en: Revista de Administración Pública (N¹00-102), pp. 2379-2422.

(2011): Lecciones de Derecho Administrativo, Cuarta Edición (Valencia, Tirant Lo Blanch).

PARejo alfonso, luciano et Al. (2009): Derecho de los Bienes Públicos, Regímenes Dominicales Específicos, Propiedades Especiales (Navarra, Thomson Reuters Aranzadi), Tomo III.

PAREJO GAMIR, ROBERTO (1975): Protección registral y dominio público (Madrid, Editorial Revista de Derecho Privado).

PAREJO GAMIR, ROBERTO Y RODRÍGUEZ OLIVER, JOSÉ MARÍA (1976): Lecciones de dominio público (Madrid, ICAI).

PENAILILLO ARÉVALO, DANIEL (2007): Los bienes, la propiedad y otros derechos reales (Santiago, Editorial Jurídica de Chile).

PIGRETTI, EDUARDO (1961): “El Dominio Minero”, en: Revista Lecciones y Ensayos (№ 19), pp. 117-121.

PRECHT PIZARRO, JORGE (1983): "Naturaleza jurídica del dominio del Estado sobre las minas y de la concesión minera en la Constitución de 1980”, en: Revista Chilena De Derecho, (N¹0), pp. 727-779.

PROUDHON, JEAN BAPTISTE VÍCTOR (1839): Traité du Domaine publico ou de la distinction des bien par rapport au domaine public (Dijon, Francia). 
public (Dijon, Francia).

(1843): Traité du Domaine publico ou de la distinction des bien par rapport au domaine PUYUELO, CARLOS (1954): Derecho Minero (Madrid, Editorial Revista de Derecho Privado).

RODRÍGUEZ GARCíA, CARLOS (1992): Una nueva sistematización jurídica de las propiedades especiales (Madrid, Editorial Dykinson).

RUíz BouRgeoIS, JULIO (1942): Instituciones de Derecho de Minería Chileno (Santiago de Chile, Editorial Nascimento), Tomo I.

RUZ LÁRTIGA, GONZALO (2011): Explicaciones de Derecho Civil: Bienes (Santiago, Abeledo Perrot/Legal Publishig Chile), Tomo III.

SAINZ MORENO, FERNANDO (1999): "El dominio público: una reflexión sobre su concepto y naturaleza, cincuenta años después de la fundación de la Revista de Administración Pública "RAP", en: Revista de Administración Pública ( $\left.N^{\circ} 150\right)$, pp. 447-514.

SERNA VALLEJO, MARGARITA (2009): “Los bienes públicos: formación de su régimen jurídico”, en: González, Julio (director), Derecho de los bienes públicos, 2a edición (Valencia, Tirant Lo Blanch), pp. 39-63.

TRAORÉ, SEYDOU SÉKOU (2008): Droit des propriétés publiques (Paris, Vuibert).

VEGTING, WILHELMUS GERARDUS (S/A): Domaine public et "Res extra commercium", étude historique du droit romain, français et néerlandais (Alphen Aan den Rijn, N. Samson).

VERGARA BLANCO, ALEJANDRO (1989): "La teoría del dominio público: el estado de la cuestión", en: Revista de Derecho Público ( $\left.N^{\circ} 114\right)$, pp. 27-58.

(1990): “Teoría del Dominio Público y Afectación Minera”, en: Revista Chilena de Derecho (Vol. 17), pp. 135-159.

(1992): Principios y sistema del derecho minero: estudio histórico-dogmático (Santiago, Editorial Jurídica de Chile).

(1998): "El dominio público ante el derecho administrativo francés", en: Revista Chilena de Derecho (Vol. 25, N²), pp. 309-327.

(2001): "Sobre la irreal propiedad estatal minera," en: III Jornadas Chilenas de Derecho de Minería, Serie Seminarios ( $\left.N^{\circ} 13\right)$, pp. 213-216.

(2006): "El problema de la naturaleza jurídica de la riqueza mineral", en: Revista Chilena de Derecho (Vol. 33, N²), pp. 215-244.

(2010): Instituciones de Derecho Minero (Santiago, Abeledo Perrot, Legal Publishing). 
(2014): "La Contemporánea Regulación de la Minería en Chile. Crítica a la Teorías Tradicionales del Dominio Estatal de las Minas", en: Derecho Administrativo. Revista de Doctrina, Jurisprudencia, Legislación y Práctica ( $\left.{ }^{\circ} 93\right)$, pp. 633-654.

VILDÓSOLA FUENZALIDA, JULIO (1999): El dominio minero y el sistema concesional en América Latina y el Caribe (Caracas, OLAMI).

VILLAR PALASÍ, JOSÉ LUIS (1964): La intervención administrativa en la industria (Madrid, Instituto de Estudios Políticos).

(1968): Derecho Administrativo. Introducción y Teoría de las Normas (Madrid, Universidad de Madrid, sección de publicaciones), Tomo I.

ZÚÑIGA URBINA, FRANCISCO (2005): “Constitución y Dominio Público: Dominio Público de Minas y Aguas Terrestres", en: Revista lus et Praxis (Vol. 11, N²), pp. 65-101.

\section{JURISPRUDENCIA CITADA}

REQUERIMIENTO FORMULADO POR LA H. JUNTA DE GOBIERNO, para que el Tribunal resuelva sobre determinados artículos, suscitadas durante la discusión del proyecto de Ley orgánica Constitucional sobre Concesiones Mineras, invocando el artículo 82, № 2, de la Constitución Política de la República (1981): Tribunal Constitucional 9 de noviembre de 1981 (requerimiento), en: http://www.tribunalconstitucional.cl/ver.php?id=611.

CONTROL DE CONSTITUCIONALIDAD DEL PROYECTO DE LEY ORGÁNICA CONSTITUCIONAL SOBRE CONCESIONES MINERAS (1981): Tribunal Constitucional 22 de diciembre de 1981 (control de constitucionalidad), en: http://www.tribunalconstitucional.cl/ver.php?id=598.

CONTROL DE CONSTITUCIONALIDAD DEL PROYECTO DE LEY QUE MODIFICA LA LEY № 18.097, ORGÁNICA CONSTITUCIONAL SOBRE CONCESIONES MINERAS (1983): Tribunal Constitucional 6 de septiembre de 1983 (control de constitucionalidad), en: http://www.tribunalconstitucional.cl/ver. php?id=591.

\section{NORMAS JURÍDICAS CITADAS}

\section{ARGENTINA}

LEY N²4.498, que modifica el Código de Minería Nacional. Boletín Oficial, 19 de julio de 1995.

\section{CHILE}

DECRETO SUPREMO $\mathrm{N}^{\circ}$ 100. Constitución Política de la República de Chile. Diario Oficial, 22 de septiembre de 2005.

DECRETO CON FUERZA DE LEY NÚMERO 1, que fija el texto refundido, coordinado y sistematizado del Código Civil. Diario Oficial, 30 de mayo de 2000. 
LEY N 18.248, CÓDIGO DE MINERÍA. Diario Oficial, 14 de octubre de 1983.

LEY Nº 18.097, ORGÁNICA CONSTITUCIONAL DE CONCESIONES MINERAS. Diario Oficial, 21 de enero de 1982.

ESPAÑA

CONSTITUCIÓN ESPAÑOLA, 1978. Boletín Oficial del Estado Número 311, 29 de diciembre de 1978.

LEY 54/1980, DE MODIFICACIÓN DE LA LEY 22/1973, DE MINAS, con especial atención a los recursos minerales energéticos. Boletín Oficial del Estado Número 280, 5 de noviembre de 1980.

LEY 33/2003, DEL PATRIMONIO DE LAS ADMINISTRACIONES PÚBLICAS, Boletín Oficial del Estado Número 264, 04 de noviembre de 2003.

LEY 47/2003, GENERAL PRESUPUESTARIA. Boletín Oficial del Estado Número 284, 27 de noviembre de 2003.

VENEZUELA

DECRETO NO. 2.165, CON RANGO, VALOR Y FUERZA DE LEY ORGÁNICA QUE RESERVA AL ESTADO LAS ACTIVIDADES DE EXPLORACIÓN Y EXPLOTACIÓN DEL ORO Y DEMÁS MINERALES ESTRATÉGICOS. Gaceta Oficial No. 6.210 Extraordinaria, 30 de diciembre de 2015. 